\title{
Ciclos políticos, socioeconomia e a geografia eleitoral do estado da Bahia nas eleições de 2006
}

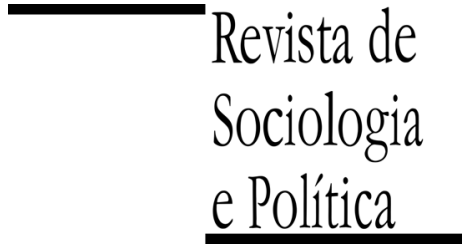

DOI 10.1590/1678-987315235407

\section{Daniel Carvalho e Gervásio Ferreira dos Santos}

\begin{abstract}
Resumo
O objetivo do artigo é analisar se interações socioeconômicas, políticas, espaciais e dos programas de transferência de renda governamental determinaram os resultados das eleições nos municípios do estado da Bahia, para o cargo de governador, em 2006. Essa eleição marcou a interrupção do controle político por parte de uma coligação partidária e grupo político também conhecido na literatura de Ciência Política como "carlismo", a partir da vitória do candidato do Partido dos Trabalhadores (PT). A literatura sobre economia dos ciclos políticos foi utilizada como base teórica. Foi elaborado um banco de dados sobre resultados eleitorais e variáveis socioeconômicas, a partir das bases de dados do Tribunal Superior Eleitoral (TSE), do Tribunal Regional Eleitoral do Estado da Bahia (TRE-BA), do Instituto Brasileiro de Geografia e Estatística (IBGE), da Federação das Indústrias do Estado do Rio de Janeiro (FIRJAN) e do Ministério do Desenvolvimento Social (MDS). Baseado nesse banco de dados, foram aplicados métodos de estatística espacial e econometria espacial associados a procedimentos de espacialização e georreferencialmento de dados. Os resultados da análise exploratória de dados espaciais indicam que os votos do PT, nas eleições no estado da Bahia de 2006, estão parcialmente correlacionados no espaço. Com a modelagem econométrica, foi comprovado que as defasagens espaciais dos votos petistas são estaticamente significantes, dado p-valor das defasagens $\rho$ e $\lambda$ nos modelos adotados. As estimações econométricas mostraram as variáveis socioeconômicas tiveram pouco efeito sobre os resultados nos municípios. O sucesso do PT nas eleições para governador do Estado da Bahia em 2006 esteve fortemente estruturado na base eleitoral prévia e na associação dos votos locais para Presidente da República, denominado no artigo de "efeito Lula". Quanto ao Programa Bolsa Família, este apresentou efeito causal direto na votação do PT para o cargo de presidente, mas não sobre os resultados da eleição para governador, o que não descarta o fato de que o efeito do programa tenha sido decisivo no agregado do eleitorado. Os resultados mostraram que os determinantes puramente locais podem não ter sido suficientes para determinar a vitória do PT para o cargo de governador e a respectiva derrota do "carlismo" nas eleições de 2006. Por outro lado, a interação espacial entre os municípios teve efeito sobre a determinação dos resultados das eleições nos municípios, dando surgimento a clusters de bases eleitorais politicamente estruturadas. A pesquisa pode auxiliar no desenvolvimento de trabalhos sobre a discussão do processo eleitoral no Brasil e os diferentes níveis de desenvolvimento socioeconômico local. Além disso, abre espaço para análises com desagregações espaciais mais "finas" em áreas urbanas, por exemplo.
\end{abstract}

PALAVRAS-CHAVE: estado da Bahia; ciclos políticos; resultados eleitorais; econometria espacial; Programa Bolsa Família.

Recebido em 21 de Janeiro de 2014. Aprovado em 2 de Abril de 2014.

\section{Introdução ${ }^{1}$}

\footnotetext{
${ }^{1}$ Agradecemos ao Prof. André Luis Mota dos Santos, à Fundação de Amparo à Pesquisa do Estado da Bahia (Fapesb) e aos pareceristas anônimos da Revista de Sociologia e Política.

${ }^{2}$ A coalizão política formada no estado da Bahia em torno da liderança de Antônio Carlos Magalhães (1927-2007) é identificada na literatura de
}

$\mathrm{O}$ objetivo deste trabalho é analisar as interações socioeconômicas e políticas que determinaram os resultados das eleições para o cargo de governador do estado da Bahia em 2006. Em particular, será verificado se as políticas sociais estabelecidas em nível federal tiveram efeito determinante sobre esses resultados eleitorais. O processo eleitoral no estado da Bahia, em 2006, ficou marcado no Brasil pelo fim do controle político do governo estadual por parte de uma coligação partidária e grupo político também conhecido como "carlismo"2. O respectivo grupo político foi originário do regime ditatorial e que contabilizou décadas de domínio posteriormente ao processo de redemocratização no Brasil. Além dessas características, o processo eleitoral também ficou marcado pelo resultado inesperado, em primeiro turno, na qual foi obtida a vitória pelo candidato do Partido dos Trabalhadores (PT). 
Ciência Política pelo termo "carlismo". De acordo com Dantas Neto (2007), a corrente "carlista" pode ser vista sob três ângulos: como poder pessoal de ACM, como o grupo político que ele comandou por muito tempo e como versão baiana da política da modernização conservadora brasileira.
Entre as mais importantes vias de transmissão dos efeitos da democracia na economia está presente à realização de eleições. Enquanto a literatura que demonstra a natureza econômica do processo eleitoral reporta-se aos trabalhos de Downs (1957), Nordhaus (1975b), Hibbs (1977), Alesina (1987), Rogoff e Sibert (1988), Rogoff (1990), Caleiro (2004) e Fialho (1999). Já as referências sobre os efeitos espaciais nos resultados eleitorais, como a utilização do respectivo instrumental estatístico são descritas por Almeida (2012) e Mariani (2011). Sobre as aplicações empíricas, o impacto dos gatos sociais nas preferências dos eleitores é o objeto de estudo de Barberia e Avelino (2011), Bouldin e Brown (2012) e Bursztyn (2010). Os resultados gerais mostram que as decisões de votos dos eleitores dos municípios mais pobres, e de necessidades mais imediatas, são sensíveis a projetos de maior visibilidade eleitoral.

O presente trabalho auxilia no entendimento da natureza econômica e espacial do processo eleitoral, sendo apresentada uma revisão das principais abordagens teóricas sobre o tema. A literatura mostra, a princípio, que os eleitores nem sempre são bem informados, o que pode incentivar os governos a utilizarem instrumentos de política econômica com fins eleitorais. Entretanto, a capacidade dos eleitores de distinguirem a competência dos candidatos pode tomar a forma de especificidades políticas locais, seja por simpatia pré-estabelecida a um grupo político específico, seja por existência de um "multiplicador social" entre os eleitores vizinhos. Essa literatura tem crescido recentemente e tem motivado a incorporação explícita dos efeitos espaciais em equações econométricas utilizadas para explicar os determinantes dos resultados eleitorais em países ou regiões

Na análise do contexto político recente do estado da Bahia, o amplo domínio eleitoral do ex-senador Antônio Carlos Magalhães (ACM) foi interrompido numa conjuntura nacional desfavorável que determinou uma perda de importância gradual do grupo. A abordagem específica sobre o tema pode ser encontrada em Borges (2010), Monteiro (2009; 2011) e Souza (2009). Segundo os autores, a coalizão política de ACM tradicionalmente tinha como uns dos trunfos para a consolidação do poder a concentração de recursos por organizações multilaterais em territórios menores, mais pobres e menos urbanizados. Entretanto, a consolidação da federalização de políticas sociais redistributivas promoveu um forte instrumento de campanha em favor da candidatura do maior adversário político no estado, o então ministro de Relações Internacionais do governo Lula, Jaques Wagner, do PT. Desse modo, alguns problemas de pesquisa podem ser colocados: $(i)$ as transferências de recursos do PBF aumentaram as votações percentuais municipais do PT na eleição para o cargo de governador do estado da Bahia no ano de 2006? (ii) existem efeitos de interação espacial entre os resultados eleitorais dos municípios vizinhos que elevaram o desempenho eleitoral do PT no mesmo ano? Qual foi o papel da eleição presidencial nos resultados da eleição estadual?

A econometria espacial, que vem se desenvolvendo a partir de impulsos teóricos, metodológicos e tecnológicos, tornou-se um campo fértil para a efetivação dessas análises, o que motivou a utilização do respectivo instrumental neste trabalho. Com base na hipótese de que os gastos federais podem modificar os resultados eleitorais no estado da Bahia, e que existem efeitos de interação espacial significantes na determinação desse resultado, serão aplicadas as metodologias de análise exploratória de dados espaciais e modelagem de econométrica espacial. Essas metodologias possibilitarão a melhor interpretação da votação municipal do PT, partido de oposição, ao cargo de governador do Estado da Bahia em 2006. Isso porque a metodologia permite o controle de efeitos de autocorrelação espacial nos resultados eleitorais. 
Além desta introdução, o artigo é composto de mais quatro seções. Na segunda seção será apresentada a compreensão do estudo de caso, ou seja, o fenômeno da modificação da geografia eleitoral no estado da Bahia, configurado em 2006. Na terceira seção será apresentada a abordagem teórica que demonstra a natureza econômica do processo eleitoral. A seção IV descreverá a metodologia da análise exploratória de dados espaciais, os modelos de controle da dependência espacial e a descrição do banco de dados a ser utilizado. $\mathrm{Na}$ seção V serão apresentados os resultados da análise exploratória de dados espaciais e as estimações econométricas. Finalmente, na seção VI serão apresentadas as considerações finais.

\section{O processo eleitoral no estado da Bahia}

\section{II.1 Contexto político após a redemocratização}

\footnotetext{
${ }^{3}$ Em 2007, o PFL partido mudou de nome para recuperar sua imagem. O novo nome escolhido foi o de

"Democratas", com a sigla DEM.
}

Ao fim do regime militar brasileiro, em 1985, o domínio político das instituições nacionais e regionais permaneceu sob o controle de forças partidárias conservadoras. No período posterior à transição democrática, coalizões tradicionais seguiram em apoiar o aparato de políticas estaduais clientelistas. O sucesso eleitoral da permanente distribuição estratégica de cargos e recursos públicos entre correligionários políticos (deputados, prefeitos e eleitores) tornou-se evidente na região Nordeste. Nessa região, uma maior importância federal foi conquistada em especial pelos grupos do ex-senador Antônio Carlos Magalhães, do Partido da Frente Liberal (PFL) ${ }^{3}$ no estado da Bahia e do ex-presidente José Sarney do Partido do Movimento Democrático Brasileiro (PMDB), nos estados do Maranhão e Amapá (Monteiro 2009).

A consolidação de oligopólios eleitorais e partidários é apresentada pela literatura tradicional como produto, particularmente, da ampliação da autonomia administrativa e orçamentária nos estados. A descentralização política e fiscal, em 1988, permitiu às coalizões tradicionais estaduais a obtenção de recursos importantes e necessários para construção e reprodução de máquinas subnacionais. O controle sobre as instituições e o poder de representação dos interesses regionais frente ao poder nacional foi restrito a um pequeno grupo de chefes políticos, que segundo os pesquisadores eram adeptos de práticas autoritárias e anti-republicanas (Borges 2010).

A renúncia do poder pelos militares, e consequentemente o retorno das eleições diretas, permitiram às demais forças políticas conservadoras (da direita e centro-direita) atribuir diferentes interesses sobre os procedimentos democráticos nacionais. Isso possibilitou a proliferação da "patronagem política" e a consequente demonstração da fragilidade institucional da democracia brasileira. Desse modo, as coalizões dominantes subnacionais garantiram a estabilidade do regime e minimizaram as discussões para possíveis reformas políticas, reformas legislativas ou reversões ao sistema de transferência fiscal. Esse sistema de transferências era responsável por atribuir o acesso dos recursos federais a redutos eleitorais desejados, sem a necessidade de redistribuir simetricamente os impostos (Monteiro 2011).

Na medida em que desempenhou um papel importante nas coalizões nacionais formadas na Nova República, a coalizão política "carlista" ganhou acesso ao poder Executivo nacional de forma regular. No plano estadual, ACM e seus correligionários adotaram a alocação estratégica de cargos e verbas para segurar parcela importante da oposição de centro. Ao mesmo tempo, submeteram as prefeituras não alinhadas ao Executivo estadual a um verdadeiro bloqueio financeiro. Ao final dos anos 1990, a oposição havia sido drasticamente reduzida no estado da Bahia. O grupo "carlista" detinha o controle de quase $90 \%$ das 
417 prefeituras e $75 \%$ dos deputados na Assembleia Legislativa estadual (Borges 2010).

Entretanto, na recente posição da política brasileira, há evidências de que o processo político brasileiro, nos estados que eram considerados como sistemas exemplares da política oligárquica, tornou-se cada vez mais competitivo e fragmentado no decorrer dos últimos anos. As elites políticas e os partidos que haviam conquistado um amplo domínio em estados como Piauí, Rio Grande do Norte, Bahia, Maranhão e Ceará, sofreram sérias derrotas para coalizões de esquerda e centro-esquerda entre os anos de 2002 e 2006 (idem). Uma boa parte dessas perdas para as tradicionais oligarquias estaduais chegou às mãos de políticos de esquerda menos propensos a fazer concessões para a direita. Isso representou temporariamente uma ameaça existencial ao modelo de governo tradicional nessas regiões (Monteiro 2009).

As diferenças organizacionais entre os partidos conservadores e os de esquerda também contribuíram para determinar as dimensões espaciais de competição política nas regiões brasileiras. Historicamente, a maioria dos partidos conservadores foi estabelecida internamente pelas elites políticas no Congresso, enquanto os de esquerda foram mobilizados por organizações sociais e movimentos populares. A direita sempre usufruiu do acesso ao direito, como por exemplo, no patrocínio ao regime autoritário. Em contraste, o PT, por exemplo, e os outros partidos de esquerda como PPS, PSB e PCdoB se dedicaram a constituição de uma forte ligação entre a liderança partidária e suas bases (idem).

\section{II.2. O estado da Bahia e a política nacional de transferência de renda}

No estado da Bahia, o amplo domínio político do até então PFL foi interrompido no ano de 2006. Esse controle ainda era originário do regime ditatorial brasileiro. Um dos trunfos para a consolidação do poder pelo PFL foi quebrado com fim do monopólio clientelista sobre gastos públicos sociais em territórios menores, pobres e menos urbanizados. Um contexto nacional de oposição desfavorável aos "carlistas" fez com que estes ficassem de fora no processo de consolidação da federalização de políticas sociais redistributivas, sob a forma do Programa Bolsa Família (PBF). Esse programa promoveu um forte instrumento de campanha em favor da candidatura do principal adversário político estadual do PFL no estado da Bahia nas eleições de 2006. Entende-se que a expansão do PBF possibilitou uma maior distribuição de recursos sob a forma de transferência direta de renda. Essa transferência reduziu a interferência das lideranças clientelistas locais e ampliou a base eleitoral do PT de regiões em que antes eram menores.

Como uma das principais políticas para manter o domínio eleitoral no estado, o PFL executou o programa distributivo "Produzir". Esse programa se baseava no financiamento, por meio de empréstimos do Banco Internacional para Reconstrução e Desenvolvimento (BIRD) e por parte do Banco Mundial (BM). No início da década de 1990, o BM decidiu modificar a gestão do programa em um modelo de Fundo Social, termo que caracteriza o financiamento de projetos específicos por frentes de organizações multilaterais. Os fundos eram disponibilizados com a função de aumentar as oportunidades socioeconômicas para as populações rurais mais pobres, como por meio do fornecimento de água (poços), energia, pontes, tratores, esgotos (principalmente banheiros) e moinhos de grãos, além de financiamentos a pequenas empresas não agrícolas como padarias, artesanatos e lavanderias (Souza 2009).

Instituído pela Lei n. 10.836, de 9 de janeiro de 2004, e regulamentado pelo Decreto n. 52.089, de 17 de setembro de 2004, o PBF é um programa de 
transferência direta de renda com condicionalidades que beneficia as famílias em situação de pobreza e extrema pobreza. O caráter universal do programa era, de encontro ao programa Produzir, que exigia licitações questionáveis para projetos comunitários. O PBF aumentou a eficiência e a transparência nos gastos públicos, visto que os benefícios eram e continuam sendo pagos diretamente às famílias por meio de cartão bancário. Também foi observada a emancipação parcial das mesmas famílias em relação aos fundos sociais que mantinham as redes de clientelistas dominantes nos municípios mais pobres. Isso decorre do fato de que existem outras opções de política que puderam ser incluídas juntamente com o PBF, tendo a exemplo a obrigatoriedades das famílias (ou pais) beneficiadas manterem os filhos matriculados e frequentando a escola.

\section{II.3. Resultados eleitorais no estado da Bahia}

O principal representante da oposição ao "carlismo" nas eleições estaduais de 2006 foi o candidato Jaques Wagner, do PT, eleito governador com 52,89\% dos votas válidos, no primeiro turno das eleições. Considerando a disputa presidencial no período, também foi confirmada a aprovação do governo do PT em nível federal com a reeleição do candidato a presidente Luís Inácio Lula da Silva (Lula), após uma disputa em dois turnos e obtenção de 60,8\% dos votos válidos. Entre as possíveis hipóteses sobre os motivos da vitória dos candidatos Lula, em nível nacional, e Jaques Wagner, em nível estadual, os analistas destacam a importância do PBF no primeiro governo Lula, especialmente nas regiões Norte e Nordeste do Brasil.

A análise em nível municipal mostrou que os prefeitos no estado da Bahia anteriormente aliados ao "carlismo" consideraram a candidatura petista de oposição eleitoralmente viável. Essa candidatura contava com o suporte do presidente da república, que era candidato a uma reeleição com elevada popularidade entre as camadas mais pobres da população. A candidatura à reeleição do presidente Lula se beneficiava do bom crescimento da economia e pelo sucesso das políticas federais de combate à pobreza. Por fim, o pragmatismo político das bases municipais "carlistas", principalmente nos pequenos municípios, empurrou-as na direção da candidatura oposicionista na perspectiva de manter-se ao lado das prováveis forças vitoriosas nos pleitos nacional e estadual, para garantir recompensas futuras na forma do acesso a cargos e verbas (Borges 2010). Esse cenário político contribuiu de forma significativa para a modificação na geografia eleitoral no estado da Bahia, como pode ser visualizado na Figura 1.

A Figura 1 apresenta a votação percentual do PT ao cargo de governador do estado da Bahia entre 1998 e 2006. Embora a expressão eleitoral do partido em 1998 ainda fosse reduzida, foi possível observar que as regiões de maiores votações eram relativamente concentradas na Microrregião de Porto Seguro e na Região Metropolitana de Salvador, regiões com renda per capita consideravelmente maior que o resto do estado. Em 2002, a distribuição de votos foi ampliada. É perceptível, na Figura 1, o crescimento e espalhamento para bolsões territoriais, em que o candidato do PT (Jaques Wagner) já possuía acima de 50\% dos votos válidos. Embora fosse possível encontrar regiões (em destaque na Mesorregião Centro Sul) de maior resistência em favor da coalizão do PFL, o número de vitórias petistas nos municípios foi cada vez maior.

Sobre o contexto citado, o desafio do artigo é responder às seguintes perguntas, já antecipadas na seção introdutória: $(i)$ as transferências de recursos do PBF aumentaram as votações percentuais municipais do PT na eleição para o cargo de governador do estado da Bahia no ano de 2006? (ii) Existem efeitos de interação espacial entre os resultados da eleição dos municípios vizinhos que 
Figura 1 - Votação percentual do PT ao cargo de governador do Estado da Bahia

Eleições 1998 (A)

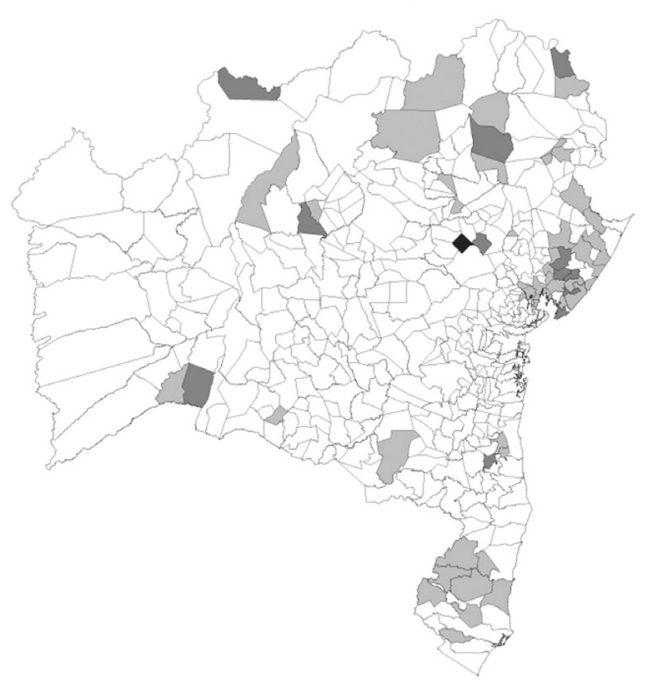

Eleições 2006 (C)

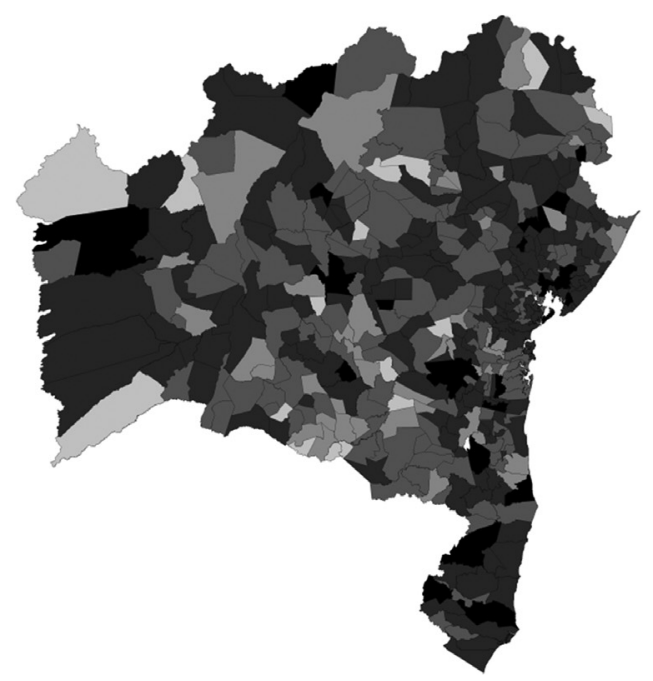

Eleições 2002 (B)

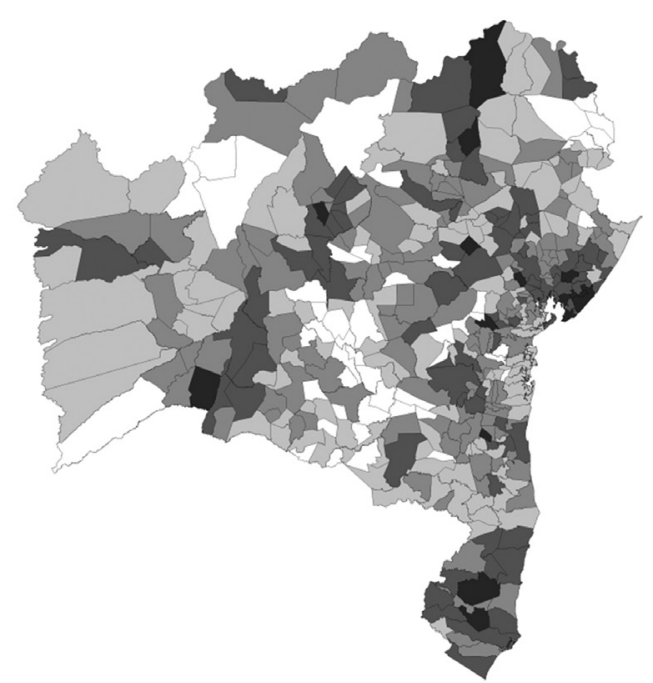

Legenda

Abaixo de $15,01 \%$

$15,01 \%$ a $25,00 \%$

$25,01 \%$ a $35,00 \%$

$35,01 \%$ a $50,00 \%$

$50,01 \%$ a $65,00 \%$

Acima de 65,00\%

Fonte: Os autores, a partir de Brasil (2011).

elevaram o desempenho eleitoral do PT no mesmo ano? (iii) Qual foi o papel da eleição presidencial nos resultados da eleição estadual? Para responder a essas perguntas, serão aplicadas técnicas de econometria espacial sobre um conjunto de variáveis econômicas, políticas, sociais e geográficas. No entanto, para que o respectivo fenômeno eleitoral possa ser modelado econometricamente, é necessário sustentá-lo a partir de abordagens teóricas sobre a natureza econômica e política do processo eleitoral, o comportamento de eleitores e partidos e as respectivas interações socioeconômicas e espaciais que ocorrem nesse processo. Essa sustentação teórica é desenvolvida na próxima seção.

\section{Democracia, economia e gastos sociais}

\section{III.1. Democracia e ciclos eleitorais}

Entre as mais importantes vias de transmissão dos efeitos da democracia na economia está presente à realização de eleições. As primeiras teorias da econô- 
mica política chegaram a supor que o governo eleito determinaria as decisões ótimas de acordo com uma função de bem-estar social. Entretanto, os teóricos da escola da escolha pública desmistificaram o comportamento de ditador benevolente do governo, sendo o pressuposto básico da teoria do bem-estar preterido pelo comportamento egoísta dos agentes políticos (Caleiro 2004).

Downs (1957) apresenta um modelo básico de eleições, baseado na teoria econômica do voto. $\mathrm{O}$ autor parte do estabelecimento de regras de comportamento para governos democráticos, bem como das implicações dessas regras. Segundo o autor, os governos democráticos agem racionalmente para maximizar o apoio político. As metas dos governos são estabelecidas sob três condições básicas: (i) uma estrutura política democrática que permite aos partidos de oposição existir; (ii) uma atmosfera de variados graus de incerteza e (iii) um eleitorado de eleitores racionais. Para planejar as políticas, de maneira a ganhar votos, o governo deve descobrir algum relacionamento entre o que ele faz e como os cidadãos votam. Baseado no axioma de que os eleitores são racionais, supõe-se que os cidadãos direcionam seus votos para os partidos que poderão fornecer mais benefícios a eles. Nesse sentido, diante de várias alternativas mutuamente exclusivas, o eleitor racional sempre considera votar em alguém que resultará na mais alta utilidade para ele, ceteris paribus, o que significa agir em seu próprio interesse.

Os primeiros estudos a respeito da existência de ciclos eleitorais tiveram origem basicamente na publicação "The Political Business Cycle" de Nordhaus (1975a), que pode ser considerado uma das primeiras formalizações realizadas no sentido de explicar a questão. De acordo com Nordhaus apud Fialho (1999), os governos podem estimular a demanda agregada antes das eleições, explorando as vantagens de uma curva de Phillips de curto prazo, por meio de uma significativa redução do desemprego, ao custo de uma pequena inflação. Após o período eleitoral, as expectativas se ajustam, aumentando ainda mais a inflação. Os efeitos expansionistas do período anterior são eliminados pela contração da demanda agregada, levando a uma recessão logo após as eleições (idem). A aplicação da hipótese de expectativas adaptativas para o setor privado foi compartilhada posteriormente por Hibbs (1977) no seu trabalho "Political Parties and Macroeconomic Policy". Segundo Hibbs apud Fialho (1999), os partidos são representados por classes sociais com preferências políticas diferentes e consequentemente apresentam preferências econômicas distintas. Partidos "progressistas" se identificariam mais com classes sociais hierarquicamente mais baixas que, dada às características socioeconômicas, são mais sensíveis e atentas a problemas relacionados ao desemprego e menos sensíveis a problemas relacionados à inflação. Os partidos conservadores, por outro lado, com bases eleitorais de grupos ou classes sociais mais elevadas, possui maior ênfase no combate à inflação.

Uma nova geração de teorias de ciclos emergiu nos finais da década de 1980, propondo uma melhor abordagem para analisar as interações entre a tomada de decisão por parte do setor privado e a política econômica. Uma característica comum a tais modelos é abordagem da política econômica como não exógena em relação ao resto do sistema econômico. Além disso, a racionalidade é determinante na formação das expectativas dos eleitores, embora se trabalhe com a constatação de que um ciclo eleitoral, mais curto e menos regular, pode ocorrer estocasticamente caso alguma insuficiência na informação possa impedir que o eleitorado preveja corretamente eventos cruciais. A formalização do eleitor racional em modelos de ciclos eleitorais foi elaborada, entre outros trabalhos, em "Macroeconomic Policy in Two-Party System", de Alesina (1987), "Elections and Macroeconomic Policy Cycles", de Rogoff e Sibert (1988), e "Equlibrium Political Budget Cycles", de Rogoff (1990) (Caleiro 2004). 
Na modelagem de Alesina (1987), permite-se que os partidos sejam diferentes nas suas preferências quanto às políticas econômicas, na medida em que representam eleitores com diferentes interesses ou ideologias. Alesina apud Fialho (1999) afirma que o processo eleitoral pode influenciar o estado da economia quando os eleitores, agora racionais, enfrentam resultados incertos a respeito do próprio processo. Em uma abordagem que utiliza modelo da teoria dos jogos, o autor demonstra que a incerteza sobre as políticas econômicas partidárias futuras gera incerteza sobre as variáveis econômicas, gerando flutuações econômicas. Para esse caso, o modelo demonstra que, no início de um mandato do governo de direita o produto estará abaixo do seu nível natural e o desemprego acima do seu nível natural; o raciocínio inverso pode ser para o governo de esquerda. Posteriormente ao ajustamento das expectativas, o produto e o desemprego convergem para o seu nível natural, independentemente de quem esteja no poder (Fialho 1999).

Rogoff e Sibert (1988) e Rogoff (1990) desenvolveram modelos que admitem a existência de assimetrias provisórias na informação disponível aos agentes. Esses modelos são chamados de modelos de competência e focam a questão de como os eleitores racionais prospectivos se comportam como eleitores retrospectivos. O governo, dispondo de uma vantagem temporal sobre os eleitores no conhecimento do seu desempenho real, não possui sua competência avaliada pelo setor privado de forma perfeita. Desse modo, os políticos tentam tirar proveito dessa situação para se beneficiar no ciclo eleitoral.

A análise do comportamento dos eleitores pode ser ampliada sob a observação das especificidades regionais nos resultados de uma eleição. É possível identificar os motivos que levam alguns partidos ou candidatos a receberem maior apoio eleitoral em certos locais, o que é definido na literatura como "geografia eleitoral". Tomando certas condições econômicas, sociais e culturais pré-estabelecidas, a análise de diversos fatores locais, que se relacionam no espaço de modo complexo, pode demonstrar a existência de uma simpatia pré-estabelecida à imagem de um grupo político específico. Essa análise pode afetar radicalmente as estratégias a serem adotadas pelos candidatos durante o período de campanha (Mariani 2011).

Outro fator de influência nas decisões dos eleitores é o chamado grau de interação de uma sociedade. A existência de um "multiplicador social", e os fatores inerentes ao mesmo, pode disseminar o conhecimento predominante local em um intervalo de tempo definido por cada indivíduo e a intenção de voto dos mesmos. A popularidade de cada candidato passa por um impulso inicial, positivo ou negativo, que, por influências e transmissões de ideias entre o próprio eleitorado, é disseminado a um nível micro. A proximidade espacial entre os municípios (ou regiões) é um fator propulsor da interação social de indivíduos. Essa interação pode promover a tendência de regiões contíguas apresentarem padrões semelhantes de voto. Esses padrões espaciais resultam em um grau específico de correlação espacial na votação por localidade (idem).

\section{III.2. A Ciência Política e o debate sobre eleições no Brasil}

Existe uma larga tradição de estudos estrangeiros ou estudos publicados por autores brasileiros no exterior sobre os padrões de voto e o sistema partidário brasileiro. Power e Zucco (2012) examinaram questões-chaves referentes a preferências ideológicas, econômicas e institucionais da elite política brasileira entre 1990 e 2009. Para os autores, o país apresentou uma prática sustentável da democracia que levou a atitude de convergência e estabilidade macropolítica. Nas duas últimas décadas, cabe destaque para a incorporação de novas forças da esquerda na política nacional, gerando um ordenamento direita-esquerda esperado pelos cientistas políticos. 
Em relação ao sistema partidário, Mainwaring (1997) aponta que o presidencialismo brasileiro foi afetado pela combinação de três principais fatores: $(i)$ forte combinação de poderes de forma reativa desde a Constituição de 1946 e de formas pró ativa e reativa a partir da Constituição de 1988; (ii) existência de um sistema partidário altamente fragmentado, de maneira que os presidentes geralmente constituem uma situação de governo de coalizão informal ou (excepcionalmente) de presidencialismo de minoria; (iii) a captura comparativamente indisciplinada de todas as partes torna difícil para o presidente confiar exclusivamente em canais partidários de apoio. Desse modo, o autor aponta que quando os presidentes são populares, os políticos de todos os matizes tendem a apoiá-los. Dentro desse contexto, o federalismo molda o funcionamento da democracia brasileira. Em um país heterogêneo e de tamanho continental, o federalismo dispersa o poder de forma fragmentada.

Ames (2001) aborda o problema da governabilidade no processo político brasileiro. Para o autor, uma democracia geralmente se depara com crises de inflação, desperdícios do governo e corrupção, déficits nos sistemas de previdência, serviços sociais inadequados, violência e desigualdade social. Nesse contexto, a governabilidade envolve a eficiência dos poderes Executivo e Legislativo em formular programas e políticas. Por outro lado, também dependerá da habilidade do governo na implementação dessas políticas. Um dos principais problemas que geram dificuldades nesse processo é o excesso de vetos, que tem reflexos sobre a estrutura institucional e especificamente sobre o sistema eleitoral. Desse modo, o autor apresenta ainda uma investigação movida por instrumentos quantitativos para explorar a interação entre fatores econômicos e demográficos, competição política e eventos políticos extraordinários em estados como Santa Catarina, Paraná, Maranhão, Ceará e Bahia. Essa revisão pode ser tomada como base para o presente estudo empírico.

Em relação a trabalhos de investigação empírica, também existe uma série de trabalhos que investigam o processo eleitoral no Brasil. Braga e Amaral (2013) analisaram as implicações do processo de seleção de candidatos na competição partidária no Brasil. Os autores mostram que os partidos brasileiros não são fracos e desorganizados como aponta parte da literatura. Os partidos são capazes de agir de maneira coordenada nas eleições para a Câmara, estabelecendo estratégias de acordo com elementos conjunturais. Veiga, Souza e Cervi (2011) analisaram as eleições municipais de 2004 do PT ao governo Federal. O estudo investiga a estratégia discursiva do partido tomando como objeto as estratégias do PT nas eleições de Porto Alegre e Curitiba. Os resultados mostram que houve um discurso padrão, com programas aos necessitados e empenharam fortemente na criação de uma imagem de político sensato, inteligente, capacitado e moralmente exemplar. Bohn (2011) analisou o papel dos programas de transferência de renda, em particular o PBF, sobre os deslocamentos da base eleitoral do presidente Lula entre 1989 e 2006. Os resultados econométricos mostraram que, apesar das mudanças no perfil dos eleitores, $o$ PBF não foi responsável por esses deslocamentos, uma vez que os eleitores pobres votam de forma diferente entre as regiões e, na maioria dos casos, estes já eram eleitores de Lula.

\section{III.3. Aplicações empíricas sobre gastos sociais}

Considerando as discussões preliminares dos ciclos econômicos eleitoralmente induzidos e da racionalidade do eleitor, é possível encontrar na literatura trabalhos empíricos sobre a alocação dos recursos públicos em gastos sociais e os resultados eleitorais. Na publicação "Social Spending and Elections: An Examination of Latin American Third Wave Democracies, 19802008", de Barberia e Avelino (2011), foi verificada a existência e testados os 
impactos de surtos de gastos sociais durante as corridas presidenciais em democracias recentemente restabelecidas na América Latina. Os autores identificaram a redução global dos gastos sociais durante as eleições, com aumentos simultâneos na previdência social e em programas de saúde. Os impactos eleitorais dessas políticas foram diferenciados na consolidação do processo democrático. Apenas nas unidades com instituições mais atrasadas houve o aumento dos gastos na saúde pública, sendo que em todos os países os recursos voltados à educação não foram incrementados. Segundo as investigações do trabalho, o realojamento de recursos públicos nas áreas citadas pode estar associado à busca de apoio dos constituintes da classe média e dos aposentados. Quanto à redução dos gastos sociais, esta pode ter corrido das dificuldades em função dos déficits fiscais dessas economias.

Utilizando regressões com dados municipais nacionais dos anos de 1994, 1998 e 2004, "Political Competition and Local Social Spending: Evidence from Brazil" de Bouldin e Brown (2012), tentou dar uma resposta alternativa sobre a correlação entre gastos sociais e a concorrência entre as coalizões políticas. $\mathrm{O}$ trabalho mostrou que os municípios de maior competitividade política tenderam a gastar menos com políticas sociais. Ao contrário das teorias tradicionais sobre democracia, os autores estabeleceram a disposição de recursos financeiros como um fator crítico na dinâmica eleitoral. Segundo eles, nos municípios de baixos recursos orçamentários foi comum a alternância de poder e uma maior participação dos eleitores devida à dificuldade das lideranças políticas de atender as demandas locais. Em localidades mais ricas, os políticos foram capazes de utilizar melhor as políticas sociais, como também outros programas de educação, saúde e construção, de modo a mobilizarem um número bem superior de votos em comparação aos seus opositores.

A tentativa de solucionar o questionamento dos baixos índices de investimento público em educação nas regiões democraticamente menos consolidadas, considerando a preferência do eleitor, é discutida em Electoral Incentives and Public Education Spending: Evidence from Brazil (Bursztyn 2010). Os resultados do estudo mostraram que os eleitores nos municípios mais pobres tendem a ser mais propensos a reeleger candidatos por priorização dos programas de transferências de renda, e não por investimentos na educação pública, se os compararmos com as bases eleitorais de municípios de rendimentos médios superiores. Para o autor, o argumento que aponta a oposição das elites como razão principal ao acesso reduzido dos pobres a educação pública de qualidade é necessariamente descartado. Entretanto, as evidências do caso brasileiro não necessariamente indicaram que os eleitores pobres subvalorizaram a educação. O que ocorre é que as necessidades imediatas foram tão urgentes que os mesmos não suportaram uma quantidade inferior de renda, mesmo que isso significasse uma menor educação dos seus filhos no futuro.

Esta seção apresentou uma revisão da literatura sobre a natureza econômica do processo eleitoral, abordando os resultados de processos eleitorais com base em condicionantes políticos, socioeconômicos e geográficos. Foi dado um enfoque particular aos gastos com políticas sociais, tendo em vista o contexto dos problemas de pesquisa apresentados. Na próxima seção, serão apresentadas as metodologias de análise exploratória de dados espaciais e de econometria espacial, bem como os detalhes do banco de dados a ser utilizado para o tratamento empírico dos problemas de pesquisa. Neste trabalho, considera-se que além das interações socioeconômicas e políticas, as interações espaciais entre os eleitores são possíveis, uma vez que a análise da geografia eleitoral no estado da Bahia mostrou que houve um padrão de penetração dos votos do PT no estado, a partir da Microrregião de Porto Seguro e da Região Metropolitana de Salvador, e que se espalhou para o restante do estado a partir de 1998. 


\section{Análise exploratória e econometria espacial}

IV.1. Metodologia da análise exploratória de dados espaciais

Entre as diferentes formas de medir a correlação espacial entre atributos de uma mesma variável aleatória, em diferentes localizações no espaço, o Índice Global de Moran (I de Moran) é o mais utilizado. O índice representa uma medida geral de associação existente num conjunto de dados sob a forma de produto cruzado pela variância dos dados $\left(z^{\prime} z\right)$, conforme Almeida (2012). A forma algébrica e matricial do $I$ de Moran é dada por:

$$
I=\frac{n}{S o} \frac{\sum_{i} \sum_{j} w_{i j} z_{i} z_{j}}{\sum_{i=1}^{n} z_{i}^{2}}
$$

Na equação (1) acima, $n$ representa o número de regiões, $z$ refere-se aos valores da variável de interesse padronizada, $\mathrm{Wz}$ representa os valores médios da variável de interesse padronizada nos vizinhos segundo uma matriz (de vizinhança) por ponderação espacial $W, w_{i j}$ é um elemento da matriz com o fim de identificar as regiões $i j$, e por fim temos que $S o$ é igual ao somatório dos elementos da matriz de pesos espaciais.

$\mathrm{O}$ índice $I$ de Moran varia de $-1 \mathrm{a}+1$. Ao contrário de um coeficiente de correlação ordinário, essa estatística não é centrada em zero. A princípio, é necessário violar a hipótese nula, que indica a igualdade da estatística $I$ e seu valor esperado $\{-[1 /(n-1)]\}$. Em situações de que o valor de $I$ excede o valor esperado temos a autocorrelação positiva que revela uma similaridade entre os valores do atributo estudado e da localização do atributo. Em ocorrências de valores $I$ abaixo do valor esperado, é identificada a autocorrelação negativa que por sua vez revela uma dissimilaridade entre os valores do atributo estudado e da localização do atributo (Almeida 2012).

A abordagem visual da autocorrelação espacial por coeficiente $I$ de Moran é baseado em diagramas de dispersão, representados por nuvens de pontos representando as regiões. Sob os eixos horizontal e vertical temos a variável de interesse ( $y$ ) e a defasagem espacial da variável (Wy) em padronização da média em zero e variância unitária, sendo transformadas e apresentadas em um diagrama como $z$ e $W z$.

A equação (2) de $W z$, abaixo, permite determinar a declividade da dispersão linear dos pontos por Mínimos Quadrados Ordinários (MQO), em que $\alpha$ é um constante, $\beta$ o coeficiente angular e $\varepsilon$ o termo de erro aleatório da regressão. A ilustração gráfica da dispersão de Moran será apresentada no item V.1.

$$
W z=\alpha+\beta z+\varepsilon
$$

Enquanto o I de Moran anterior nos diz como o conjunto de dados está distribuído no espaço por indicadores de associação linear, o "Local Indicator of Spatial Association" (LISA) é responsável por indicar clusters significantes e os diferentes padrões espaciais locais. Embora os indicadores locais sejam proporcionalmente uma decomposição de um indicador global, a existência dos clusters e outliers modificam o agrupamento dos dados nas regiões, o que incapacita a utilização de padrões globais para tais fins.

O indicador $I$ de Moran local $\left(I_{i}\right)$ atende às condições satisfatórias do indicador LISA, permitindo identificar aglomerações e dispersões locais significantes. Assim como o índice global, o $I_{i}$ local varia entre -1 a +1 e o valor esperado da estatística da região $i$ toma a forma da expressão - $[$ wi/ $(n=1)]$. O $I_{i}$ local incorpora somente as informações de $i$ e seus vizinhos, definidos confor- 
me uma matriz de pesos espaciais. Sabendo que $z_{i}$ é a variável de interesse padronizada na região $i, z_{j}$ é a variável de interesse padronizada nas regiões $(j)$ vizinhas de $i$ e $w_{i j}$ é a defasagem espacial de $i$ e $j$, o coeficiente de $I_{i}$ é descrito na equação abaixo.

$$
I_{i}=z_{i} \sum_{j=1}^{J} w_{i j} z_{j}
$$

A análise de clusters é uma técnica de análise exploratória multivariada que permite a agregação de variáveis em grupos homogêneos consoante o seu grau de semelhança. Sabendo que por autocorrelação espacial local (I de Moran) cada unidade de observação há um $I_{i}$ específico e seu respectivo nível de significância, a apresentação do conjunto de dados pode por mapeamento de clusters (LISA MAP) categorias de associação espacial enquanto agrupamentos estaticamente significantes. A ilustração dos agrupamentos citados será apresentada no item V.2. O índice LISA mede a autocorrelação espacial local e a associação dessa autocorrelação com a intensidade da variável de análise no local e nos vizinhos é que possibilita construção dos mapas de clusters.

IV.2. Modelagem da dependência espacial

Sob o ponto de vista metodológico, a diferença entre a econometria convencional e a econometria espacial concentra-se na incorporação explícita dos efeitos espaciais na regressão. Os modelos espaciais podem representar não apenas o padrão de interação socioeconômica entre os agentes num sistema, mas também como as características da estrutura desse sistema se interagem no espaço. Na presença dos efeitos espaciais, algumas das hipóteses do Modelo Clássico de Regressão Linear (MCRL) são violadas, o que indica a necessidade de métodos de análise alternativos aos Mínimos Quadrados Ordinários (MQO), característicos da econometria convencional (Almeida 2012). No presente trabalho, serão utilizados três métodos de modelagem dos efeitos espaciais: Modelo Autorregressivo Espacial, Modelo de Erro Espacial e o Modelo Espacial Geral.

No Modelo Autorregressivo Espacial (ou SAR, de Spatial Auto Regressive) a variável dependente $y$ é influenciada por uma variável endógena $W y$, que é nada menos que a variável defasada de $y$. Logo, segundo o modelo os valores de $y$ nas regiões vizinhas influencia o valor da variável $y \mathrm{em}$ um processo de casualidade multidirecional. Segue abaixo a versão resumida do modelo SAR:

$$
y=\rho W y+X \beta+\varepsilon
$$

Caso o coeficiente de defasagem espacial $\rho$ for positivo, a autocorrelação espacial global tende a ser positiva, desde que se obedeça a restrição de que o parâmetro $\rho$ se situe no intervalo aberto entre -1 e 1. A hipótese de validação da relação causal no modelo SAR indica que nenhuma variável explicativa contida na matriz $X$ pode estar correlacionada o termo de erro aleatório. Entretanto, em tais modelos de defasagens está presente a multidirecionalidade dos processos espaciais: a variável defasada $W y$ é endógena e se encontra correlacionada com $\varepsilon$.

No Modelo de Erro Espacial (ou SEM, de Spatial Error Model), também identificado, a variável dependente $y$ é influenciada por uma variável residual defasada $W \xi$, que nada mais é que a associação do componente do termo de erro aleatório $(\varepsilon)$ com a média dos erros verificados nas regiões vizinhas $(\lambda W \xi)$. De certa forma, os fatores aleatórios não incluídos no modelo estariam autocorrelacionados espacialmente. Segue abaixo a versão resumida do modelo SEM:

$$
y=X \beta+\xi
$$




$$
\xi=\lambda W \xi+\varepsilon
$$

Nessa modelagem espacial, os efeitos de $\xi$ não podem ter relação de correlação com nenhuma variável explicativa. A incorporação de novos multiplicadores espaciais na expressão também é possível desde que o módulo do parâmetro de erro autorregressivo $(\lambda)$ seja inferior a 1 . Entre as razões do surgimento da autocorrelação residual, uma explicação plausível está na incapacidade de se modelar toda a fonte de dependência espacial oriunda do processo estocástico gerador dos dados espaciais (idem).

Por fim, no Modelo Espacial Geral (também conhecido como modelo SAC) a variável dependente $y$ é influenciada não apenas por uma variável endógena $W y$, como também por uma variável residual defasada $W \xi$. Logo, segundo o modelo, o valor de $y$ e $\varepsilon$ nas regiões vizinhas influenciam o valor da variável $y$ em um processo de casualidade multidirecional. Segue abaixo a versão resumida do modelo SAC:

$$
\begin{aligned}
& y=\rho W_{1} y+X \beta+\xi \\
& \xi=\lambda W_{2} \xi+\varepsilon
\end{aligned}
$$

Sob as propriedades do SAC, os módulos dos coeficientes de defasagem espacial $\rho$ e do parâmetro de erro autorregressivo $\lambda$ são necessariamente menores que 1, com o fim evitar o comportamento instável da modelagem. A interpretação dos coeficientes de inclinação $\beta$ é a mesma indicada no modelo o SAR, independente das diferenças entre as matrizes $W$. No modelo, o termo de erro além de estar autocorrelacionado espacialmente também é heterocedástico, o que amplia o impacto do uso da defasagem por conta do efeito multiplicador (idem).

Uma vez detectada a presença da autocorrelação espacial no percentual de votos petistas é preciso verificar o modelo mais adequado na determinação dessa autocorrelação. Desse modo, serão estimados os três modelos acima e a escolha do melhor modelo será feita com base nos procedimentos sugeridos por Florax, Folmer e Rey (2003). Uma síntese do método também pode ser encontrada em Almeida (2012). Em linhas gerais, os procedimentos são:

(i) Estimar o modelo clássico de análise de regressão linear por MQO;

(ii) Testar a hipótese de ausência de autocorrelação espacial devido a uma defasagem ou a um erro, por meio do valor do multiplicador de Lagrange para defasagem espacial (ML $\rho$ ) e Multiplicador de Lagrange para o erro espacial (ML $\lambda)$

(iii) Se ambos os testes não forem estatisticamente significantes, a utilização do modelo clássico é mais apropriada. Caso contrário será necessário seguir o próximo passo;

(iv) Caso ambos sejam estatisticamente significantes será necessário estimar o modelo apontado como o mais significante, de acordo com as versões robustas dos testes, ou seja, o multiplicador de Lagrange robusto para a defasagem espacial (MLR $\rho$ ) e o multiplicador de Lagrange robusto para o erro espacial (MLR $\lambda$ ). Caso MLR $\rho>$ MLR $\lambda$, identifica-se o modelo com defasagem espacial como o mais apropriado. Caso contrário, MLR $\rho<\operatorname{MLR} \lambda$, adota-se o modelo de erro espacial como o mais apropriado.

No entanto, cabe ainda ressaltar que a complexidade do processo de autocorrelação espacial pode fazer com que esse processo ocorra conjuntamente, tanto na variável dependente quanto no termo de erro, conforme o modelo SAC. Logo, esse modelo também será estimado e o respectivo multiplicador de Lagrange Robusto também poderá ser utilizado. 
IV.3. Banco de dados

${ }^{4}$ Algumas estatísticas descritivas das variáveis, apresentadas no Anexo 1.
Para o estudo dos fatores de efeito no resultado eleitoral em destaque no artigo, é necessária a construção de um banco de dados do conjunto de variáveis a serem utilizadas. Sob a posse dos dados, é apresentado, na próxima seção, a análise exploratória dos dados espaciais e as estimações econométricas. A partir da indicação do problema de pesquisa, do referencial teórico e da metodologia, são apresentadas as variáveis municipais no item posterior.

O banco de dados construído permite contemplar diferentes aspectos sobre os municípios do estado da Bahia. As variáveis que constituem esse banco de dados são apresentadas na Tabela $1^{4}$. Entre as variáveis de caraterística política e eleitoral, foram utilizadas as bases de dados virtuais do Tribunal Superior Eleitoral (TSE) e do Tribunal Regional Eleitoral do Estado da Bahia (TRE-BA). Sobre a variável de distância, a capital Salvador foi aplicada à equação de distância entre dois pontos, tomando as coordenadas geográficas municipais presentes nos mapas digitais do Instituto Brasileiro de Geografia e Estatística (IBGE). A variável do desenvolvimento municipal foi obtida na página específica do índice, presente no portal da Federação das Indústrias do Estado do Rio de Janeiro (FIRJAN). Quanto à variável da cobertura de famílias atendidas pelo PBF (por município), a mesma foi obtida através da divisão do número de famílias beneficiadas pelo programa (disponível na base de dados virtual do MDS) sobre o número total de famílias (estimado pelos dados do Censo Demográfico do IBGE). As demais variáveis têm como fonte a base de dados virtual do Ministério do Desenvolvimento Social (MDS). Na análise exploratória de dados espaciais também foram considerados os votos do PT ao cargo de governador do estado da Bahia no ano de 1998.

Tabela 1 - Detalhamento do banco de dados

\begin{tabular}{lccc}
\hline Variável & Código & Fonte & Tipo \\
\hline $\begin{array}{l}\text { Percentual dos votos válidos em } 2006 \text { do candidato Jaques Wagner do PT para } \\
\text { o cargo de governador da Bahia }\end{array}$ & VtGov06 & TSE & contínua \\
$\begin{array}{l}\text { Percentual dos votos válidos em } 2006 \text { do candidato Lula do PT para o cargo } \\
\text { de Presidente da República }\end{array}$ & VtPres06 & TSE & contínua \\
$\begin{array}{l}\text { Percentual dos votos válidos em } 2002 \text { do candidato Jaques Wagner do PT para } \\
\text { o cargo de governador da Bahia }\end{array}$ & VtGov02 & TSE & contínua \\
$\begin{array}{l}\text { Percentual dos votos válidos em 2002 do candidato Lula do PT para o cargo } \\
\text { de Presidente da República }\end{array}$ & VtPres02 & TSE & contínua \\
$\begin{array}{l}\text { Filiação do prefeito do município ao Partido dos Trabalhadores (PT) no ano } \\
\text { de 2006 }\end{array}$ & PrefPT & TSE \\
$\begin{array}{l}\text { Filiação do prefeito do município a outro partido da coligação eleitoral do } \\
\text { Partido dos Trabalhadores (PT) do estado da Bahia no ano de 2006 }\end{array}$ & ColPT & TSE \\
$\begin{array}{l}\text { Distância (em quilômetros) de um município para a capital do estado da Bahia } \\
\text { (Salvador) }\end{array}$ & DistSal & IBGE \\
$\begin{array}{l}\text { População absoluta para o ano de 2006 } \\
\text { Produto Interno Bruto (PIB) per capita para o ano de 2006 }\end{array}$ & discreta \\
$\begin{array}{l}\text { Índice FIRJAN de Desenvolvimento Municipal (IFDM) consolidado para o } \\
\text { ano de 2006 }\end{array}$ & IFDM \\
$\begin{array}{l}\text { Participação do número de famílias atendidas pelo Programa Bolsa Família } \\
\text { (PBF) sobre o total de famílias do mesmo munícipio para o ano de 2006 }\end{array}$ & Cob_PBF & MDS \\
\hline
\end{tabular}

Fonte: Os autores, com base em Brasil (2011; 2012); IGBE (2012; 2014) e FIRJAN (2012). 


\title{
V. Resultados: o padrão espacial e os determinantes dos resultados eleitorais no estado da Bahia
}

\author{
V.1. Análise exploratória de dados espaciais
}

${ }^{5} \mathrm{O}$ critério de vizinhança (ou contiguidade), é utilizado para ordenar as informações ao longo do espaço, refletindo a posição de uma unidade em relação às demais. Os dois critérios de contiguidade mais utilizados na econometria são "Rainha" e "Torre". Em "Rainha" todos municípios com fronteiras ou vértices em comuns são considerados vizinhos; em "Torre", somente os locais com fronteira em comum. Para mais detalhes, ver Almeida (2012).
Esta seção apresenta a análise exploratória de dados espaciais, tomando como variável de interesse o percentual de votos do candidato do PT ao cargo de governador nos municípios do estado da Bahia entre os anos de 1998 e 2006.

De acordo com a análise exploratória do indicador de autocorrelação espacial global I de Moran e das evidências estatísticas exibidas no Gráfico 1, foi possível rejeitar a hipótese nula da aleatoriedade espacial num nível de significância de $0,001 \%$. Utilizando a matriz de vizinhança tipo Rainha ${ }^{5}$ de $1^{\mathrm{a}}$ ordem de contingência (conforme Almeida 2012), foi possível observar que o coeficiente $I$ de Moran indicou que a votação relativa do PT nos municípios do estado da Bahia para o cargo de governador em entre 1998 e 2006 foi autocorrelacionada espacialmente.

A palavra "espalhamento" indica uma expansão da votação do PT para o cargo de governador da Bahia em 2002. Anteriormente, com uma base eleitoral e concentração espacial de votos reduzida, o PT ampliou suas antigas bases eleitorais e conquistou novas, de modo em que as áreas de concentração dos eleitores petistas cresceram e se encontram mais distribuídas no mapa eleitoral baiano, o que possivelmente está associado com um maior valor do I de Moran.

De 1998 a 2002 houve uma maior variação dos percentuais de votos do PT entre os municípios do estado da Bahia. Em 1998, havia uma maior concentração espacial de votos em poucas microrregiões do estado da Bahia e o índice de autocorrelação espacial foi $I=0,26$. Pelo gráfico de dispersão de Moran no Gráfico 2, foi possível observar que embora os percentuais de votos estivessem autocorrelacionados espacialmente, havia uma elevada concentração do padrão de votos. Em 2002, a autocorrelação espacial aumentou para $I=0,35$, porém, com uma maior variação dos votos entre os municípios e com um padrão menos heterogêneo. No ano da vitória do PT, em 2006, o índice de autocorrelação espacial foi de $I=0,19$. Embora este seja menor que em 2002, é possível observar que a autocorrelação se dá sobre um padrão de percentuais de votos mais homogêneos entre os municípios do estado da Bahia. A menor autocorrelação espacial em 2006 no resultado pode ser interpretada como uma expansão do partido em muitas áreas anteriormente consideráveis como redutos "carlistas" e de reduzida influência petista. Os gráficos de dispersão de Moran confirmam a análise a apresentada no mapa de porcentagens, apresentados no Gráfico 1.

Com base no índice local LISA e utilizando os mesmos dados que geraram as análises anteriores (mapas de percentis e I global de Moran), são exibidos, na Figura 2, os mapas de clusters da votação do PT ao cargo de governador do Estado da Bahia entre 1998 e 2006. Esses mapas classificam os agrupamentos de votação do PT no estado da Bahia por agrupamentos Alto-Alto (AA), Baixo-Baixo (BB), Baixo-Alto (BA), Alto-Baixo (AB) e não significante. Na análise de clusters foi possível identificar todos os tipos de agrupamentos nos mapas, nos quais existe autocorrelação espacial e a concentração de percentuais de votos em maior ou menor intensidade.

É possível observar, na Figura 2, que a maior extensão de áreas ficou ocupada por municípios que não apresentaram estatística de significância para a formação de agrupamentos de votos (branco). Esses municípios ficaram espalhados principalmente nas Mesorregiões do Extremo Oeste, Vale São-Franciscano e Nordeste Baiano. Os municípios que se destacaram pelo alto desempenho do PT se concentraram nos agrupamentos AA, espalhados na Região Metropolitana de Salvador e no Sul Baiano. No Centro Sul Baiano foi identifi- 
Gráfico 1 - Autocorrelação espacial dos votos municipais do PT ao cargo de governador do Estado da Bahia por matriz rainha $\left(1^{\mathrm{a}}\right.$ ordem $)$

Eleições 1998 (A)

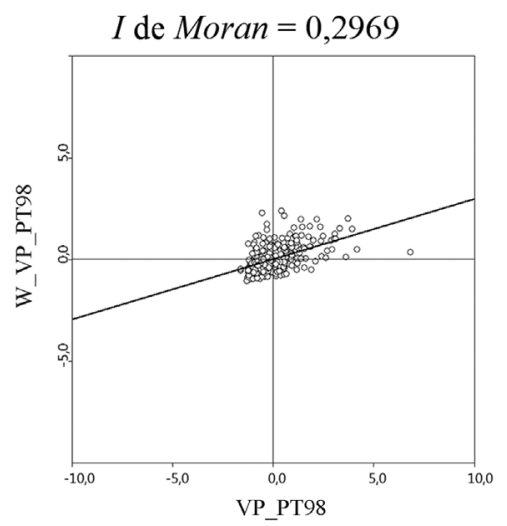

Eleições 2002 (B)

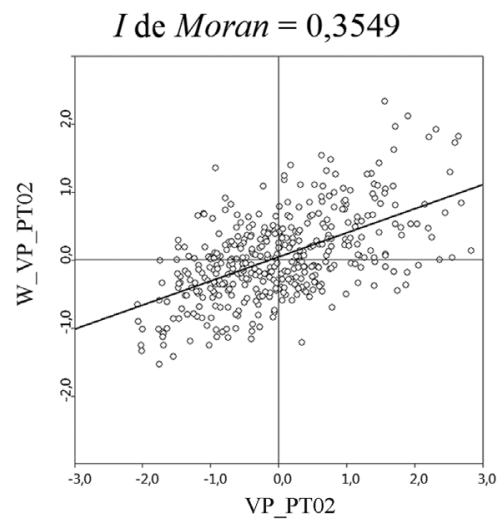

Eleições 2006 (C) I de Moran = 0,1906

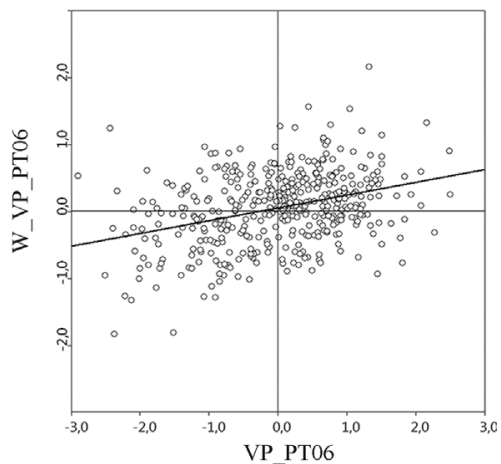

Fonte: Os autores, a partir de Brasil (2011).

cado o fenômeno oposto, a autocorrelação espacial positiva BB indicou a possível presença de áreas de resistência e de predominância das forças políticas tradicionais até então. Quanto às localidades $\mathrm{AB}$ e $\mathrm{BA}$, estas geralmente ficaram próximas de agrupamento $\mathrm{AA}$ e $\mathrm{BB}$, sendo reduzidas em quantidade e insuficientes para inverter a inclinação positiva da reta do coeficiente $I$ de Moran global.

\section{V.2. Resultados econométricos}

As estimações econométricas foram realizadas utilizando quatro modelos: Modelo Linear Geral; Modelo de Defasagem Espacial (SAR); Modelo de Erro Autorregressivo Espacial (SEM) e o Modelo Espacial Geral (SAC). Esses modelos são apresentados na Tabela 1, com o suporte do software estatístico e econométrico Open GeoDa. O primeiro modelo foi estimado através método de Mínimos Quadrados Ordinários (MQO) e os demais que modelam a defasagem espacial foram estimados através do método de Máxima Verossimilhança (MV). O método MV produz estimadores mais eficientes que o método MQO, a partir da garantida da normalidade do termo de erro (ALMEIDA, 2012). A variável dependente refere-se ao percentual de votos do candidato do PT, Jaques Wagner, ao cargo de governador, nos municípios do estado da Bahia, no ano de 2006. As demais variáveis explicativas são descritas na Tabela 1.

Modelo Linear Geral:

VtGov06 $=\beta$ o $+\beta_{1}$ Vtpres $06+\beta_{2}$ VtGov $02+\beta_{3}$ VTpres $02+$

$\beta_{4}$ prefPT $+\beta_{5}$ ColPT $+\beta_{6} \log ($ DistSal $)+\beta_{7} \log ($ Popul $)+$

$\beta_{8} \log (P I B p c)+\beta_{9} I F D M+\beta_{10} C o b_{-} P B F+\varepsilon$

Modelo SAR:

VtGov06 $=\beta o+\beta_{1}$ Vtpres $06+\beta_{2}$ VtGov02 $+\beta_{3}$ VTpres $02+$

$\beta_{4}$ prefPT $+\beta_{5}$ ColPT $+\beta_{6} \log ($ DistSal $)+\beta_{7} \log ($ Popul $)+$

$\beta_{8} \log ($ PIBpc $)+\beta_{9} I F D M+\beta_{10}$ Cob_PBF $_{-} \rho W V t$ Gov $06_{1}+\varepsilon$

Modelo SEM:

VtGov06 $=\beta$ o $+\beta_{1}$ Vtpres $06+\beta_{2}$ VtGov $02+\beta_{3}$ VTpres $02+$

$\beta_{4}$ prefPT $+\beta_{5}$ ColPT $+\beta_{6} \log ($ DistSal $)+\beta_{7} \log ($ Popul $)+$

$\beta_{8} \log (P I B P c)+\beta_{9} I F D M+\beta_{10}$ Cob_PBF $+\rho W V t G o v 06_{2}+\varepsilon$ 
Figura 2 - Mapas de cluster dos votos municipais do PT ao cargo de governador do Estado da Bahia por matriz Rainha (1 ${ }^{\mathrm{a}}$ ordem)

Eleições 1998 (A)

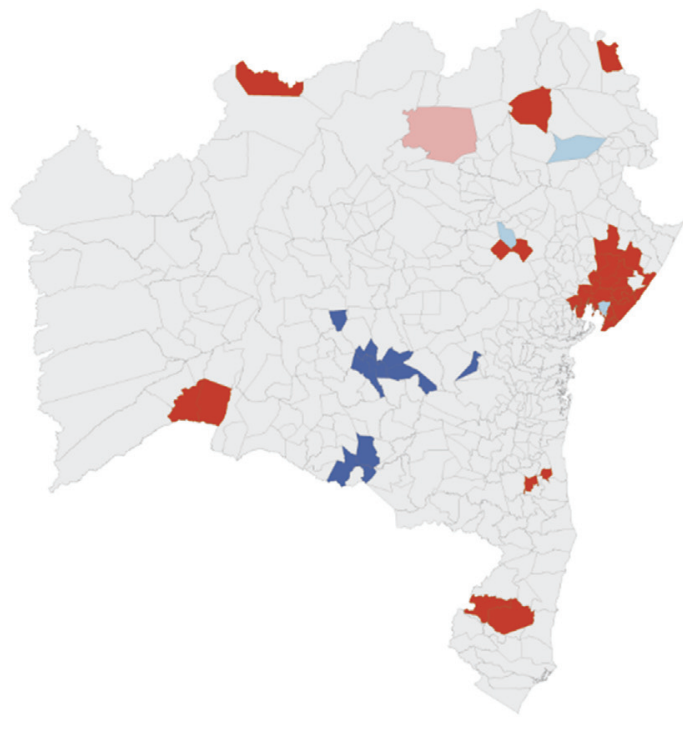

Eleições 2006 (C)

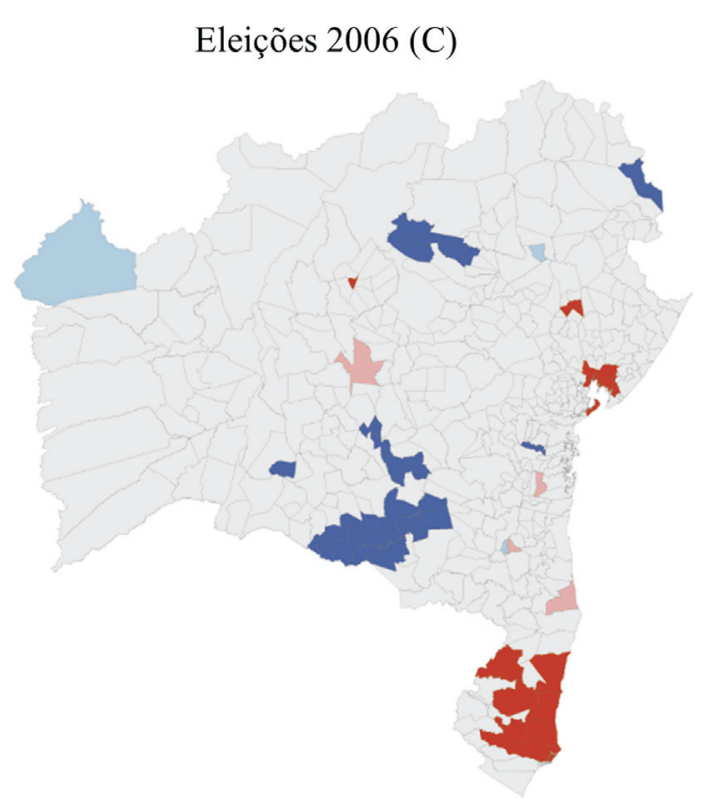

Eleições 2002 (B)

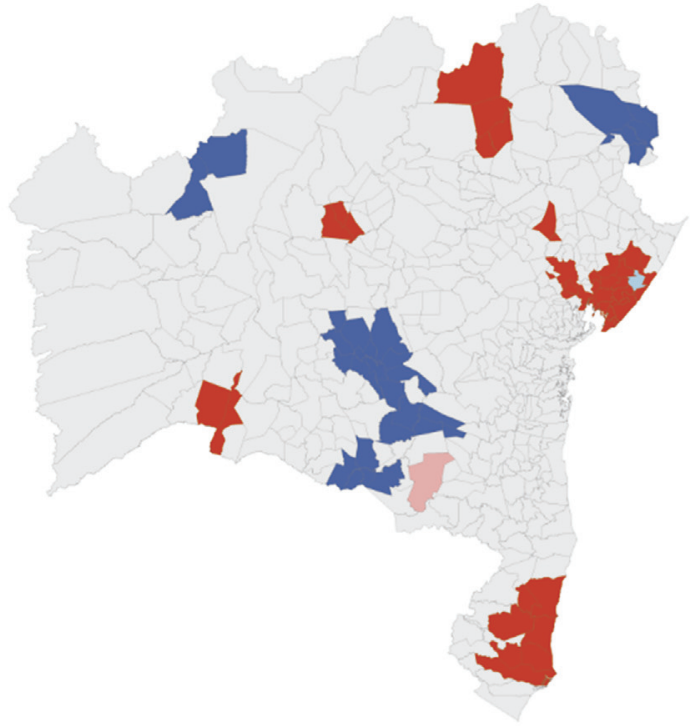

Legenda

Não Significante

Alto-Alto (AA)

Alto-Baixo (AB)

Baixo-Alto (BA)

Baixo-Baixo (BB)

Fonte: Os autores, a partir de Brasil (2011).

Modelo SAC:

VtGov06 $=\beta$ o $+\beta_{1}$ Vtpres $06+\beta_{2}$ VtGov $02+\beta_{3}$ VTpres $02+\beta_{4}$ prefPT +

$\beta_{5}$ ColPT $+\beta_{6} \log ($ DistSal $)+\beta_{7} \log ($ Popul $)+\beta_{8} \log ($ PIBpc $)+$

$\beta_{9}$ IFDM $+\beta_{10}$ Cob_PBF $+\rho W V t$ Gov06 $+\lambda W V t G o v 06_{2}+\varepsilon$

Os resultados das estimações são apresentados na Tabela 2. Os modelos com a modelagem da autocorrelação espacial foram estimados utilizando o

${ }^{6}$ Para fins didáticos também foram realizadas regressões sob o critério de vizinhança Torre, em que são considerados apenas os municípios limítrofes por um ponto como critério de construção da matriz de vizinhança tipo Rainha ${ }^{6}$, conforme Almeida (2012). Inicialmente, a estimação por MQO mostrou, através do coeficiente de determinação $\mathrm{R}^{2}$, que as variáveis explicativas selecionadas explicam $51,7 \%$ da variação na participação dos votos do PT para governador. O $p$-valor nulo referente à estatística $F$ mostrou que essas variáveis são estatisticamente signifi- 
vizinhos. Sobre esse modelo, as magnitudes dos parâmetros mantiveram-se muito próximas e a significância desses parâmetros não sofreram cantes para o modelo, conjuntamente. Quanto à significância individual, a interpretação dos parâmetros será feita a partir da significância da defasagem espacial, uma vez que a análise exploratória de dados espaciais já detectou a presença de autocorrelação espacial na variável dependente.

Tabela 2 - Estimações econométricas da votação percentual do PT ao cargo de governador do Estado da Bahia em 2006

\begin{tabular}{|c|c|c|c|c|}
\hline \multicolumn{5}{|c|}{ Variável dependente: VtGov06 } \\
\hline \multirow[t]{2}{*}{ Tipo de regressão } & \multirow[t]{2}{*}{ MQO } & \multicolumn{3}{|c|}{ Matriz Raiz ( $1^{\circ}$ ordem de cont.) } \\
\hline & & SAR & SEM & SAC \\
\hline \multirow[t]{2}{*}{ Constante } & $-0,428 * * *$ & $-0,4388 * * *$ & $-0,4494 * * *$ & $-0,4011 * * *$ \\
\hline & $-0,1266$ & $-0,1253$ & $-0,1285$ & $-0,1342$ \\
\hline \multirow[t]{2}{*}{ VtPres06 } & $0,7025 * * *$ & $0,6933 * * *$ & $0,6904 * * *$ & $0,6969 * * *$ \\
\hline & $-0,0588$ & $-0,0589$ & $-0,0599$ & $-0,0615$ \\
\hline \multirow[t]{2}{*}{ VtGov02 } & $0,4359 * * *$ & $0,4309 * * *$ & $0,4132 * * *$ & $0,4025 * * *$ \\
\hline & $-0,0769$ & $-0,0759$ & $-0,077$ & $-0,0775$ \\
\hline \multirow[t]{2}{*}{ VtPres02 } & $-0,1081$ & $-0,1076$ & $-0,0798$ & $-0,0548$ \\
\hline & $-0,0719$ & $-0,071$ & $-0,0725$ & $-0,0732$ \\
\hline \multirow[t]{2}{*}{ PrefPT } & 0,0036 & 0,003 & 0,0029 & 0,0046 \\
\hline & $-0,0219$ & $-0,0216$ & $-0,0215$ & $-0,0212$ \\
\hline \multirow[t]{2}{*}{ ColPT } & $-0,0403 * * *$ & $-0,0408 * * *$ & $-0,0473 * * *$ & $-0,0508 * * *$ \\
\hline & $-0,0149$ & $-0,0147$ & $-0,0146$ & $-0,0145$ \\
\hline \multirow[t]{2}{*}{$\log ($ DistSal $)$} & $0,025^{*}$ & $0,0263 *$ & 0,027 & 0,0233 \\
\hline & $-0,015$ & $-0,0149$ & $-0,0168$ & $-0,0193$ \\
\hline \multirow[t]{2}{*}{$\log ($ Popul $)$} & $0,0481 * * *$ & $0,0476^{* * *}$ & $0,0488 * * *$ & $0,0509 * * *$ \\
\hline & $-0,0152$ & $-0,015$ & $-0,0152$ & $-0,0153$ \\
\hline \multirow[t]{2}{*}{$\log (\mathrm{PIBpc})$} & 0,0026 & $-0,0005$ & $-0,0016$ & 0,0062 \\
\hline & $-0,0237$ & $-0,0236$ & $-0,024$ & $-0,025$ \\
\hline \multirow[t]{2}{*}{ IFDM } & 0,1535 & $0,1679 *$ & $0,2015^{* *}$ & $0,1867 *$ \\
\hline & $-0,0995$ & $-0,0987$ & $-0,1$ & $-0,1037$ \\
\hline \multirow[t]{2}{*}{ Cob_PBF } & 0,067 & 0,07 & 0,0839 & $0,0897 *$ \\
\hline & $-0,0539$ & $-0,0532$ & $-0,0537$ & $-0,0538$ \\
\hline \multirow[t]{2}{*}{ WVtGov06 ( $\rho)$} & & 0,0418 & & $-0,1741^{* *}$ \\
\hline & & $-0,057$ & & $-0,0727$ \\
\hline \multirow[t]{2}{*}{ WVtGov06 $(\lambda)$} & & & $0,1679 * *$ & $0,3192 * * *$ \\
\hline & & & $-0,0747$ & $-0,0682$ \\
\hline Observações & 417 & 417 & 417 & 417 \\
\hline $\mathrm{R} 2$ & 0,5173 & 0,518 & 0,5245 & 0,5336 \\
\hline p-valor de F & 0 & & & \\
\hline p-valor da Razão de Verossimilhança & & 0,4774 & 0,0431 & 0,0196 \\
\hline Critério Akaike & $-852,025$ & $-850,53$ & $-856,116$ & $-856,151$ \\
\hline \multicolumn{5}{|c|}{ Multiplicador de Lagrange: $\operatorname{ML} \rho=0,4828, \operatorname{ML} \lambda=3,6375^{*}$} \\
\hline \multicolumn{5}{|c|}{ Multiplicador de Lagrange Robusto: MLR $\rho=0,9636, \operatorname{MLR} \lambda=4,1183^{* *}$} \\
\hline \multicolumn{5}{|c|}{ * - Estatística significante com probabilidade de rejeição em $10 \%$} \\
\hline \multicolumn{5}{|c|}{ ** - Estatística significante com probabilidade rejeição em 5\% } \\
\hline$* * *$ - Estatística significante com prob & le de rejeição & & & \\
\hline
\end{tabular}

Fonte: Os autores, com base em Brasil (2011; 2012); IGBE (2012; 2014) e FIRJAN (2012). 
modificações, o que indica uma possível robustez do modelo proposto.
Com relação aos modelos defasagem espacial na variável dependente, no erro ou em ambos, foi possível observar inicialmente que as estimações não diferiram muito com a alteração no critério de construção da matriz, seja no valor dos parâmetros, seja na significância estatística dos mesmos. Os modelos com defasagem espacial nos votos do PT ao cargo de governador em 2006 (SAR) não demonstraram significância estatística nessa variável para nenhum dos dois critérios de vizinhança escolhidos. O modelo com defasagem espacial no erro (SEM) apresentou significância estatística no parâmetro $\lambda$, o que indicou que outros fatores aleatórios que não estão presentes no modelo estão autocorrelacionados espacialmente e ajudam a explicar os votos do PT ao cargo de governador em 2006. A inclusão desse termo fez, entre outros, que o ajuste do modelo, dados pelo coeficiente de determinação $R 2$, aumentasse de $51,7 \%$ no modelo MQO para 52,5\% no modelo SEM. No modelo SAC, que apresentou o melhor critério de ajuste, tanto o parâmetro $\rho$, referente à defasagem na variável dependente, quanto o parâmetro $\lambda$, referente à defasagem no erro, apresentaram significância estatística com ambos critérios para a matriz de vizinhança. Além disso, o coeficiente de determinação $R 2$ mostrou que esse modelo possui um grau de ajuste de $53,4 \%$, que é consideravelmente superior aos modelos anteriores.

Quanto à determinação do melhor modelo com controle espacial, os testes de multiplicador de Lagrange $L M \rho(0,4828)$ e $L M \lambda(3,6375)$ indicaram a rejeição da hipótese de não autocorrelação espacial somente nos termos de erro. Desse modo, o teste aponta diretamente para a utilização do modelo SEM, com a modelagem dos termos de erro defasados espacialmente. O modelo SAC, que também foi estimado neste caso por fins didáticos, apresentou significância estatística em ambos os parâmetros de defasagem espacial, entretanto, a magnitude dos demais parâmetros não variou substancialmente e o aumento do grau de ajuste foi muito reduzido.

Logo, tomando o modelo SEM como mais adequado para analisar os determinantes dos resultados eleitorais do PT na eleição para governador no ano de 2006, é possível observar que inicialmente as variáveis de política VtPres06 e VtGov02 apresentaram parâmetros positivos e estatisticamente significantes. De acordo com a Tabela 2, cada ponto percentual de aumento na votação de Lula (VtPres06), significa um aumento de 0,69 pontos percentuais na votação de Jaques Wagner (VtGov06), mantidas constantes as demais variáveis. Já sobre a variável VtGov02, temos que cada ponto percentual de redução dos votos petistas na eleição anterior para governador significa uma redução de 0,41 pontos percentuais na votação de Jaques Wagner em 2006 (VtGov06), mantidas constantes as demais variáveis. As variáveis de política VtPres02 e PrefPT06 não apresentaram significância estatística considerável. Com relação a ColPT06, esta variável apresentou parâmetro negativo e se apresentou estatisticamente significante em todos os modelos. Isso mostra que os votos dos candidatos a prefeitos pertencentes aos partidos (com exceção do PT) que fizeram parte da coligação liderada pelo PT foram maiores nos municípios em que o PT obteve um menor \% de votos para governador em 2006.

Em menor magnitude, a variável $\log ($ Popul) também é estaticamente significante nos modelos apresentados. Os resultados indicam que a votação do candidato Jaques Wagner cresce quanto maior é o porte populacional dos municípios. Nesse contexto, a base eleitoral petista se manteve forte nos municípios mais populosos e foi reforçada pela interiorização, por maior votação nos municípios menores. Sobre os possíveis fatores responsáveis por tal interiorização, como é possível observar nos mapas anteriores, a própria base eleitoral do candidato Lula pode ser deduzida como o principal fator. 
Com relação às demais variáveis, a variável $\log ($ DistSal $)$ apresentou significância estatística nos modelos MQO e SAR, mas com um parâmetro muito pequeno e muito próximo de zero, indicando que a distância da capital do estado não teve muito efeito sobre os resultados da eleição nos municípios, o que corrobora as estatísticas espaciais que mostram que houve um "espalhamento" considerável dos votos do PT no estado da Bahia em relação aos pleitos eleitorais anteriores a 2006. A variável em logaritmo do PIB per capita $\log (P I B p c)$ não apresentou significância estatística. A variável referente ao desenvolvimento municipal (IFDM) apresentou significância estatística, principalmente no modelo SEM. Isso mostrou que, embora o PIB per capita não tenha afetado os resultados eleitorais, o PT obteve um êxito maior nos municípios mais desenvolvidos, o que de certa forma também apontou para a dificuldade do PT em penetrar em ainda muitos municípios-redutos "carlistas".

Finalmente, a variável referente à participação das famílias no PBF $\left(C o b \_P B F\right)$ apresentou sinal positivo, mas com significância estatística de apenas $10 \%$ no modelo SAC. Desse modo, não é possível identificar evidências estatísticas de que o PBF teve efeito causal direto nos resultados eleitorais do PT na eleição para governador. Esse resultado se manteve mesmo testando outras variáveis alternativas à variável utilizada nas regressões. Duas explicações podem ser dadas em relação a esse resultado. O primeiro é o fato de que as maiorias das famílias pobres talvez estivessem localizadas em municípios pobres que eram antigos redutos "carlistas". A segunda explicação é o fato de que o programa bolsa família pudesse estar diretamente relacionado à votação do PT no estado da Bahia para Presidente da República em 2006. Desse modo, os efeitos do PBF não poderiam ser captados diretamente sobre os resultados eleitorais do PT nas eleições para governador nos municípios no mesmo ano.

Para verificar essa hipótese, foram realizadas estimações econométricas adicionais, tomando a variável dos votos do PT para Presidente nos municípios do estado da Bahia em 2006 (VtPres06) como variável dependente. A variável dos votos do PT para governador nos municípios do estado da Bahia em 2006 (VtGov2006) foi, desta vez, introduzida como variável explicativa. Os resultados são apresentados na Tabela 3.

Os coeficientes referentes às variáveis defasadas espacialmente, nos modelos espaciais, apresentarem um elevado nível de significância em relação à Tabela 2, o que reflete o maior grau dependência espacial nos votos do PT para a Presidência da República, no estado da Bahia em 2006, e também nos demais fatores aleatórios que afetaram esses votos. Nesas novas estimações, a variável referente ao PBF apresentou efeito causal sobre os votos do PT para presidente nos municípios do estado da Bahia em 2006, em todos os modelos. Desse modo, é possível concluir que, embora o PBF não tenha tido efeito causal direto sobre os resultados da votação do PT em 2006, para governador, este teve efeito causal direto na votação do PT para a Presidência da República. Essa evidência justifica a necessidade de preservação da variável que mede a votação do PT para presidente na equação de votação do PT para governador. Regressões auxiliares, sem a variável de votação do PT para presidente em 2006 e 2002, mostraram que a variável de cobertura do PBF apresentaria significância estatística na votação do PT para governador. No entanto, essas especificações gerariam estimações enviesadas devido à omissão de variáveis na equação. Além disso, a correlação (negativa) entre a variável de cobertura do PBF e as variáveis de PIB per capita e população também contribuíram para minimizar ou mesmo eliminar o efeito causal da cobertura do PBF na votação do PT para governador no estado da Bahia em 2006 (ver Anexo 2). No entanto, isso ainda não descarta a possibilidade de que os votos referentes às famílias beneficiadas pelo PBF tenham sido decisivos para o resultado agregado da respectiva eleição. 
A alta significância e valor dos parâmetros referentes à votação do candidato Lula em 2006 (VtPres06) e a votação do candidato Jaques Wagner no mesmo ano (VtGov02) mostrou que o sucesso do PT nas eleições para governador do estado da Bahia, em 2006, esteve fortemente estruturado em dois principais

Tabela 3 - Estimações econométricas da votação percentual do PT ao cargo de Presidente da República em 2006

\begin{tabular}{|c|c|c|c|c|}
\hline \multicolumn{5}{|c|}{ Variável dependente: VtPres06 } \\
\hline \multirow[t]{2}{*}{ Tipo de regressão } & \multirow[t]{2}{*}{ MQO } & \multicolumn{3}{|c|}{ Matriz Raiz $\left(1^{\circ}\right.$ ordem de cont. $)$} \\
\hline & & SAR & SEM & SAC \\
\hline \multirow[t]{2}{*}{ Constante } & $0,4736 * * *$ & $0,3260 * * *$ & $0,4911 * * *$ & $0,3708 * * *$ \\
\hline & $-0,0901$ & $-0,0903$ & $-0,092$ & $-0,0952$ \\
\hline \multirow[t]{2}{*}{ VtGov06 } & $0,3698 * * *$ & $0,3469 * * *$ & $0,3217 * * *$ & $0,3329 * * *$ \\
\hline & $-0,031$ & $-0,0295$ & $-0,03$ & $-0,03$ \\
\hline \multirow[t]{2}{*}{ VtPres02 } & $0,4645^{* * *}$ & $0,4268 * * *$ & $0,4453 * * *$ & $0,4374 * * *$ \\
\hline & $-0,047$ & $-0,0452$ & $-0,0468$ & $-0,0463$ \\
\hline \multirow[t]{2}{*}{ VtGov02 } & $-0,3423 * * *$ & $-0,3177 * * *$ & $-0,3048 * * *$ & $-0,3084 * * *$ \\
\hline & $-0,0554$ & $-0,0527$ & $-0,0538$ & $-0,0536$ \\
\hline \multirow[t]{2}{*}{ PrefPT } & $-0,0362 * *$ & $-0,0386 * * *$ & $-0,0363 * *$ & $-0,0386 * * *$ \\
\hline & $-0,0158$ & $-0,015$ & $-0,0146$ & $-0,0148$ \\
\hline \multirow[t]{2}{*}{ ColPT } & $0,0233 * *$ & $0,0227 * *$ & $0,0261 * *$ & $0,0252 * *$ \\
\hline & $-0,0108$ & $-0,0103$ & $-0,0102$ & $-0,0103$ \\
\hline \multirow[t]{2}{*}{$\log ($ DistSal $)$} & $-0,0471 * * *$ & $-0,0344 * * *$ & $-0,0422 * * *$ & $-0,0372 * * *$ \\
\hline & $-0,0107$ & $-0,0104$ & $-0,0148$ & $-0,0126$ \\
\hline \multirow[t]{2}{*}{$\log ($ Popul) } & $-0,0262 * *$ & $-0,0288 * * *$ & $-0,0229 * *$ & $-0,0272 * *$ \\
\hline & $-0,0111$ & $-0,0105$ & $-0,0108$ & $-0,0107$ \\
\hline \multirow[t]{2}{*}{$\log (\mathrm{PIBpc})$} & 0,0163 & 0,0056 & 0,0084 & 0,0046 \\
\hline & $-0,0172$ & $-0,0164$ & $-0,0174$ & $-0,0171$ \\
\hline \multirow[t]{2}{*}{ IFDM } & $-0,0278$ & 0,0301 & $-0,0252$ & 0,0133 \\
\hline & $-0,0724$ & $-0,0696$ & $-0,0716$ & $-0,0716$ \\
\hline \multirow[t]{2}{*}{ Cob_PBF } & $0,1357 * * *$ & $0,1352 * * *$ & $0,1446 * * *$ & $0,1409 * * *$ \\
\hline & $-0,0386$ & $-0,0367$ & $-0,0371$ & $-0,0371$ \\
\hline \multirow[t]{2}{*}{ WVtGov06 ( $\rho)$} & & $0,2446 * * *$ & & $0,1867 * * *$ \\
\hline & & $-0,0453$ & & $-0,054$ \\
\hline \multirow[t]{2}{*}{ WVtGov06 $(\lambda)$} & & & $0,4287 * * *$ & $0,2426 * * *$ \\
\hline & & & $-0,0623$ & $-0,0717$ \\
\hline Observações & 417 & 417 & 417 & 417 \\
\hline $\mathrm{R} 2$ & 0,5537 & 0,5864 & 0,6019 & 0,5964 \\
\hline p-valor de F & 0 & & & \\
\hline p-valor da Razão de Verossimilhança & & 0 & 0 & 0,0334 \\
\hline Critério Akaike & $-1119,6$ & $-1144,7$ & $-1151,81$ & $-1154,91$ \\
\hline \multicolumn{5}{|c|}{ Multiplicador de Lagrange: $\operatorname{ML} \rho=28,1065^{* * *}, \operatorname{ML} \lambda=30,5933^{* * *}$} \\
\hline \multicolumn{5}{|c|}{ Multiplicador de Lagrange Robusto: $\operatorname{MLR} \rho=5,664 * *, \operatorname{MLR} \lambda=8,1508 * * *$} \\
\hline \multicolumn{5}{|c|}{ * - Estatística significante com probabilidade de rejeição em $10 \%$} \\
\hline \multicolumn{5}{|c|}{ ** - Estatística significante com probabilidade rejeição em 5\% } \\
\hline *** - Estatística significante com prob & le de rejeição & & & \\
\hline
\end{tabular}

Fonte: Os autores, com base em Brasil (2011; 2012); IGBE (2012; 2014) e FIRJAN (2012). 
fatores: (i) uma base eleitoral prévia, que foi ampliada em todo o território do estado e, principalmente, (ii) pela associação dos votos do PT para a Presidência da República para os votos para governador, o chamado "efeito Lula", considerando a estratégia do candidato Jaques Wagner em vincular sua imagem a imagem do então Presidente e candidato à reeleição de Lula.

Para avaliar a sensibilidade dos votos do PT para governador em relação aos votos do PT para a Presidência da República no estado da Bahia em 2006, as equações referentes aos resultados da Tabela 2 foram estimadas sem a presença da variável dependente referente aos votos do PT para presidente nos municípios do estado da Bahia em 2006 (VtPres06). Os resultados referentes aos coeficientes de determinação $R^{2}$ são apresentados na Tabela 4. Tomando inicialmente a equação estimada por MQO, é possível observar que o grau de ajuste foi reduzido consideravelmente, caindo de $51,7 \%$ na equação estimada com VtPres06 para 30,75\% na equação sem essa variável. A diferença entre os dois valores mostra que os votos do PT para a Presidência da República, nos municípios do estado da Bahia, elevam o grau de ajuste do modelo em cerca de $20,95 \%$. Para os modelos espaciais SAR e SAM, essa diferença ficou em torno de $20,0 \%$ e, para o modelo espacial SAC, em torno de $16,0 \%$, o que reforça o efeito do candidato Lula à presidência nos resultados eleitorais do candidato a governador do estado da Bahia, Jaques Wagner, nas eleições de 2006.

\section{Conclusões}

O artigo teve como objetivo analisar as interações socioeconômicas, políticas e espaciais que determinaram os resultados das eleições para o cargo de governador do estado da Bahia em 2006. Em particular, buscou-se também analisar se o Programa Bolsa Família (PBF) teve efeito direto sobre os resultados eleitorais. Além da mudança do controle político, de "direita" para a "esquerda", o processo eleitoral no estado da Bahia também ficou marcado pelo resultado inesperado, em primeiro turno, no qual foi obtida a vitória pelo candidato do PT, Jaques Wagner. Tradicionalmente fortalecidos pela adoção de

Tabela 4 - Estimações econométricas da votação percentual do PT ao cargo de governador do Estado da Bahia em 2006 (sem as variáveis independentes da votação do PT à Presidência da República)

\begin{tabular}{|c|c|c|c|c|}
\hline \multicolumn{5}{|c|}{ Variável dependente: VtGov06 } \\
\hline \multirow[t]{2}{*}{ Tipo de regressão } & \multirow[t]{2}{*}{ MQO } & \multicolumn{3}{|c|}{$\begin{array}{c}\text { Matriz Raiz ( } 1^{\circ} \text { ordem de } \\
\text { cont.) }\end{array}$} \\
\hline & & SAR & SEM & SAC \\
\hline Observações & 417 & 417 & 417 & 417 \\
\hline $\mathrm{R} 2$ & 0,3222 & 0,3422 & 0,3593 & 0,4648 \\
\hline p-valor de F & 0 & & & \\
\hline p-valor da Razão de Verossimilhança & & 0,002 & 0,0001 & 0,0005 \\
\hline Critério Akaike & $-714,484$ & $-722,011$ & $-730,582$ & $-738,692$ \\
\hline \multicolumn{5}{|c|}{ Multiplicador de Lagrange: ML $\rho=11,0815^{* * *}, \operatorname{ML} \lambda=16,1495^{* * *}$} \\
\hline \multicolumn{5}{|c|}{ Multiplicador de Lagrange Robusto: MLR $\rho=0,0014, \operatorname{MLR} \lambda=5,0694 * *$} \\
\hline \multicolumn{5}{|c|}{ * - Estatística significante com probabilidade de rejeição em $10 \%$} \\
\hline \multicolumn{5}{|c|}{ ** - Estatística significante com probabilidade rejeição em 5\% } \\
\hline *** - Estatística significante com prob & lade de reje & eição em 1 c & & \\
\hline
\end{tabular}

Fonte: Os autores, com base em Brasil (2011; 2012); IGBE (2012; 2014) e FIRJAN (2012). 
políticas clientelistas e acesso regular ao Governo Federal, os "carlistas" passaram a enfrentar o crescimento da base eleitoral do PT no estado dada expansão das políticas sociais federais do "governo Lula".

As abordagens teóricas e uma breve revisão dos principais autores sobre a natureza econômica do processo eleitoral foram apresentadas neste trabalho. $\mathrm{O}$ que a literatura mostra, a princípio, é que os eleitores nem sempre são bem informados, o que pode incentivar os governos a utilizarem instrumentos de política econômica como forma de ter uma maior possibilidade de permanência no poder. Entretanto, a capacidade dos eleitores de distinguirem a competência dos candidatos pode tomar a forma de especificidades políticas locais, seja por simpatia pré-estabelecida à imagem de um grupo político específico, seja por existência de um "multiplicador social" entre os municípios vizinhos. Essa literatura tem crescido recentemente e tem motivado a incorporação explícita dos efeitos espaciais em equações econométricas utilizadas para explicar os determinantes dos resultados eleitorais em países ou regiões.

Os resultados do estudo empíricos mostraram que houve uma interação espacial positiva dos votos do PT nas últimas eleições do estado da Bahia, bem como a presença de clusters estatísticos de votos. As estimações econométricas mostraram inicialmente que o sucesso do PT nas eleições para governador do estado da Bahia em 2006 esteve fortemente estruturado em dois principais fatores: uma base eleitoral prévia, que foi ampliada em todo o território do estado e, principalmente, pela associação dos votos do PT para Presidente da República para os votos para governador, o chamado "efeito Lula", considerando a estratégia do candidato Jaques Wagner em vincular sua imagem a imagem do então presidente e candidato à reeleição Luiz Inácio Lula da Silva. Quanto ao PBF, este apresentou efeito causal direto na votação do PT para o cargo de presidente, porém, não apresentou efeito causal direto sobre os resultados da eleição para governador. Esse resultado não descarta o fato de que o efeito do PBF tenha sido decisivo no agregado do eleitorado baiano.

Este trabalho pode auxiliar o desenvolvimento de novos trabalhos científicos orientados à discussão de problemas políticos, econômicos e sociais regionais. A espacialidade determinada pela localização das unidades, como a base eleitoral de um partido, permite identificar e incorporar especificidades locais, como a preferência de eleitores, em um nível micro para o cálculo do modelo proposto. A interação entre os agentes, por exemplo, provavelmente afeta determinação das eleições de prefeitos, o que abre a possibilidade de uma futura aplicação sobre um grau de visualização ainda mais reduzido, como análises por bairro e setor censitário.

Daniel Carvalho (dan1elsilva@hotmail.com) é Mestrando em Economia pela Universidade Federal da Bahia (UFBA).

Gervásio Ferreira dos Santos (gervasio74@ gmail.com) é Doutor em economia pela Universidade de São Paulo (USP) e Professor da Faculdade de Economia da Universidade Federal da Bahia (UFBA).

\section{Referências}

Alesina, A. 1987. Macroeconomic Policy in a Two-Party System as a Repeated Game. The Quarterly Journal of Economics, 102(3), pp. 651-678.

Almeida, E. 2012. Econometria espacial aplicada. Campinas: Alínea.

Ames, B. 2001. The Deadlock of Democracy in Brazil. Ann Arbor: University of Michigan Press.

Barberia, L.G.; Avelino, G. 2011. Social Spending and Elections: An Examination of Latin American Third Wave Democracies, 1980-2008. Seattle: The American Political Science Association.

Bohn, S. 2011. Social Policy and Vote in Brazil: Bolsa Familia and the Shifts in Lula's Electoral Base. Latin American Research Review, 46(1), pp. 54-79.

Borges, A. 2010. Já não se fazem mais máquinas políticas como antigamente: competição vertical e mudança eleitoral nos estados brasileiros. Revista de Sociologia e Política, 18(35), pp. 167-188. 
Bouldin, C.; Brown, D.S. 2012. Political Competition and Local Social Spending: Evidence from Brazil. Boulder: University of Colorado.

Braga, M.S.S.; Amaral, O.E. 2013. Implicações do processo de seleção de candidatos na competição partidária: o caso brasileiro. Revista Sociologia e Política, 21(46), pp. 33-43.

Bursztyn, L. 2010. Electoral Incentives and Public Education Spending: Evidence from Brazil. Los Angeles: UCLA.

Caleiro, A. 2004. Democracia e economia: uma discussão em torno do papel económico das eleições. Évora: Universidade de Évora.

Dantas Neto. P.F. 2007. Carlismo: passado, presente, futuro. In: __ Gramsci e o Brasil. Disponível em: http://www.acessa.com/gramsci/?page=visualizar\&id = 761. Acesso em 23 abr.2015.

Downs, A. 1957. An Economic Theory of Political Action in a Democracy. Journal of Political Economy, 65(2), pp. $135-150$.

Fialho, T.M.M. 1999. Ciclos políticos: uma resenha dos municípios paulistas. Revista de Economia Política, 19(2), pp. 131-149.

Florax, R.J.G.M.; Folmer, H.; Rey, S.J. 2003. Specification Searches in Spatial Econometrics: The Relevance of Hendry's Methodology. Regional Science and Urban Economics, 33(5), pp. 557-579.

Hibbs, D. 1977. Political Parties and Macroeconomic Policy. The American Political Science Review, 71(1), pp. $1467-1487$.

Mainwaring, S. 1997. Multipartism, Robust Federalism, and Presidentialism in Brazil. In: S. Mainwaring; M. Shuggart, eds. Presidentialism and Democracy in Latin America. Cambridge, UK: Cambridge University Press.

Mariani, C.G.A. 2011. Aplicações da econometria espacial ao resultado da eleição presidencial de 2010 em Santa Catarina. Porto Alegre: Editora UFRGS.

Monteiro, A.P. 2009. A Reversal of Political Fortune: The Transitional Dynamics of Conservative Rule in Brazil. Northfield: Carleton College. 2011. Inequality and the Rise and Decline of Conservatives in Brazilian Democracy. Northfield: Carleton College.

Nordhaus, W. 1975a. The Political Business Cycle. The Review of Economic Studies, 42(22), pp. 169-190. 1975b. The Review of Economic Studies. The American Political Science Review, 42(2), pp. 169-190.

Power, T.; Zucco, C. 2012. Elite Preferences in a Consolidating Democracy: The Brazilian Legislative Surveys, 19902009.Latin American Politics and Society, 54(4), pp. 1-27.

Rogoff, K. 1990. Equilibrium Political Budget Cycles. The American Economic Review, 80(1), pp. 21-36.

Rogoff, K.; Sibert, A. 1988. Elections and Macroeconomic Policy Cycles. The Review of Economic Studies, 55(1), pp. 1-16.

Souza, C. 2009. Electoral Politics in Brazil with Evidence from the State of Bahia: State-Led Social Funds vs. Federal-led Social Policies. Salvador: Centro de Recursos Humanos (CRH).

Veiga, L.F.; Souza, N.R.; Cervi, E.U. 2011. Da expectativa de vitória à derrota: estratégias discursivas do PT em Curitiba e Porto Alegre em 2004. Revista Brasileira de Ciência Política, 6. pp. 99-135.

\section{Outras fontes}

Bahia. Tribunal Regional Eleitoral do Estado da Bahia. Sistema de registros de pesquisas eleitorais.

Brasil. Ministério do Desenvolvimento Social. 2011. Pesquisa de Informações Básicas Municipais. Disponível em: http://aplicacoes.mds.gov.br/sagi/simulacao/munic/munic2var.php. Acesso em: 23 abr. 2015

Brasil. Tribunal Superior Eleitoral. 2012. Eleições anteriores: candidatos eleitos - período de 1945-1990. Disponível em: http://tse.jus.br/eleicoes/eleicoes-anteriores. Acesso em: 23 abr.2015.

FIRJAN. 2012. Federação das Indústrias do Estado do Rio de Janeiro. Índice FIRJAN de Desenvolvimento Municipal. Disponível em: http://firjan.org.br/ifdm. Acesso em: 23 abr. 2012.

IBGE. 2012. Mapeamento Topográfico. Disponível em: http://ibge.gov.br/home/geociencias/default_prod.shtm. Acesso em: 23 abr. 2015.

. 2014. População. Disponível em: http://www.ibge.gov.br/home/mapa_site/mapa_site.php\#populacao. Acesso em: 23 abr. 2014. 


\section{Abstract}

The objective of this article is to analyze whether socioeconomic, political, spatial and government income transfer programs interactions determined the outcome of elections in the municipalities of the state of Bahia, to the post of governor in 2006. This election marked the interruption of political control by a party coalition and political group also known in the political science literature as "carlismo", from the victory of the candidate of the Workers Party (PT). The literature about the economy of political cycles was used as a theoretical basis. A database on electoral outcomes and socioeconomic variables was drawn from the database from the Supreme Electoral Tribunal (TSE), the Regional Electoral Court of the State of Bahia (TRE-BA), the Brazilian Institute of Geography and Statistics (IBGE), the Federation of Industries of the State of Rio de Janeiro (FIRJAN) and the Ministry of Social Development (MDS). Based on this database, methods of Spatial Statistics and Spatial Econometrics associated with data spatialization and georeferencing procedures were applied. The results of exploratory spatial data analysis indicate that PT vote in elections in the state of Bahia, 2006, were partially correlated in space. With econometric modeling, it was shown that the spatial lags of the PT votes are statically significant considering the $p$-value of $\rho$ and $\lambda$ lags in the models adopted. The econometric estimations showed that socioeconomic variables had little effect on the results in the municipalities. The success of PT elections for governor of the state of Bahia in 2006 was strongly structured in prior electoral base and the local association of votes for President, called in the paper of "Lula effect". As for the Bolsa Família Program, it presented a direct causal effect on the PT vote for President, but not on the results of the election for governor, which does not rule out the fact that the effect of the program has been important in the aggregate of the electorate. In summary, the results pointed that the purely local determinants may not have been sufficient to determine the victory of the PT for the office of governor and their defeat over "carlismo" in the 2006 elections. Moreover, the spatial interaction among the municipalities had effect on the determination of the election results in cities, giving rise to clusters of electoral bases politically structured. The research might be extended to analyze the electoral process in Brazil and the different levels of local socioeconomic development. Furthermore, it also might be extended analysis using more "fine" spatial subdivisions in urban areas, for example.

KEYWORDS: state of Bahia; political cycles; electoral outcomes; spatial econometrics; Bolsa Família Program.

License information: This is an open-access article distributed under the terms of the Creative Commons Attribution License, which permits unrestricted use, distribution, and reproduction in any medium, provided the original work is properly cited. 


\section{Anexo 1}

Tabela 1A - Estatísticas descritivas das variáveis

\begin{tabular}{lccccc}
\hline Variáveis & Observações & Média & Desvio Padrão & Mínimo & Máximo \\
\hline VtGov06 & 417 & 0,4861 & 0,1223 & 0,1318 & 0,7913 \\
VtPres06 & 417 & 0,6659 & 0,0923 & 0,3765 & 0,8594 \\
VtGov02 & 417 & 0,2775 & 0,1128 & 0,0437 & 0,5965 \\
VtPres02 & 417 & 0,4571 & 0,1270 & 0,1424 & 0,7846 \\
PrefPT & 417 & 0,0456 & 0,2088 & 0 & 1 \\
ColPT & 417 & 0,0911 & 0,2881 & 0 & 1 \\
$\log ($ DistSal & 417 & 239,5146 & 191,1682 & 0,0000 & 3264,1600 \\
$\log ($ Popul $)$ & 417 & 33453,59 & 137450,50 & 2958 & 2714018 \\
$\log ($ PIBpc $)$ & 417 & 4542,09 & 11281,77 & 530,99 & 216843,60 \\
IFDM & 417 & 0,4666 & 0,0633 & 0,2928 & 0,7333 \\
Cob_PBF & 417 & 0,5159 & 0,1059 & 0,1331 & 0,7973 \\
\hline
\end{tabular}

Fonte: Os autores, com base em Brasil (2011; 2012); IGBE (2012; 2014) e FIRJAN (2012). 


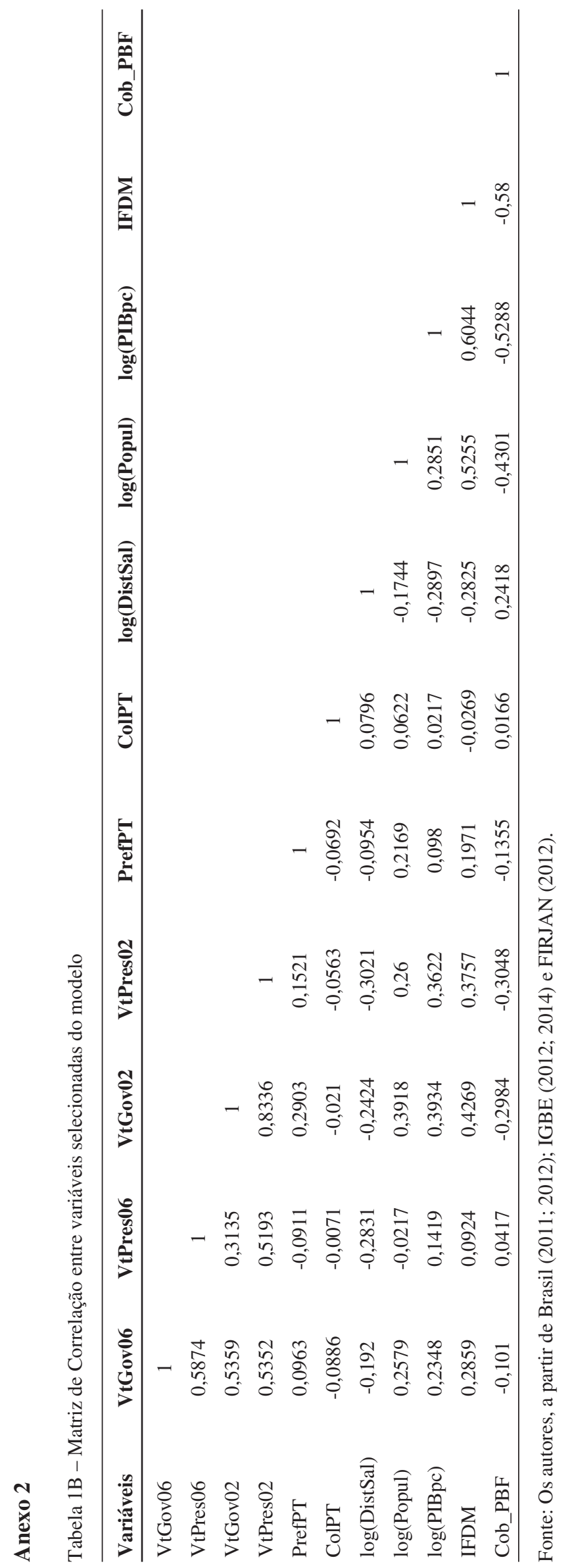

